\title{
COLEGIOS PARADIGMÁTICOS DE LA ARQUITECTURA MODERNA VALENCIA
}

Marcos Amaya Martínez*

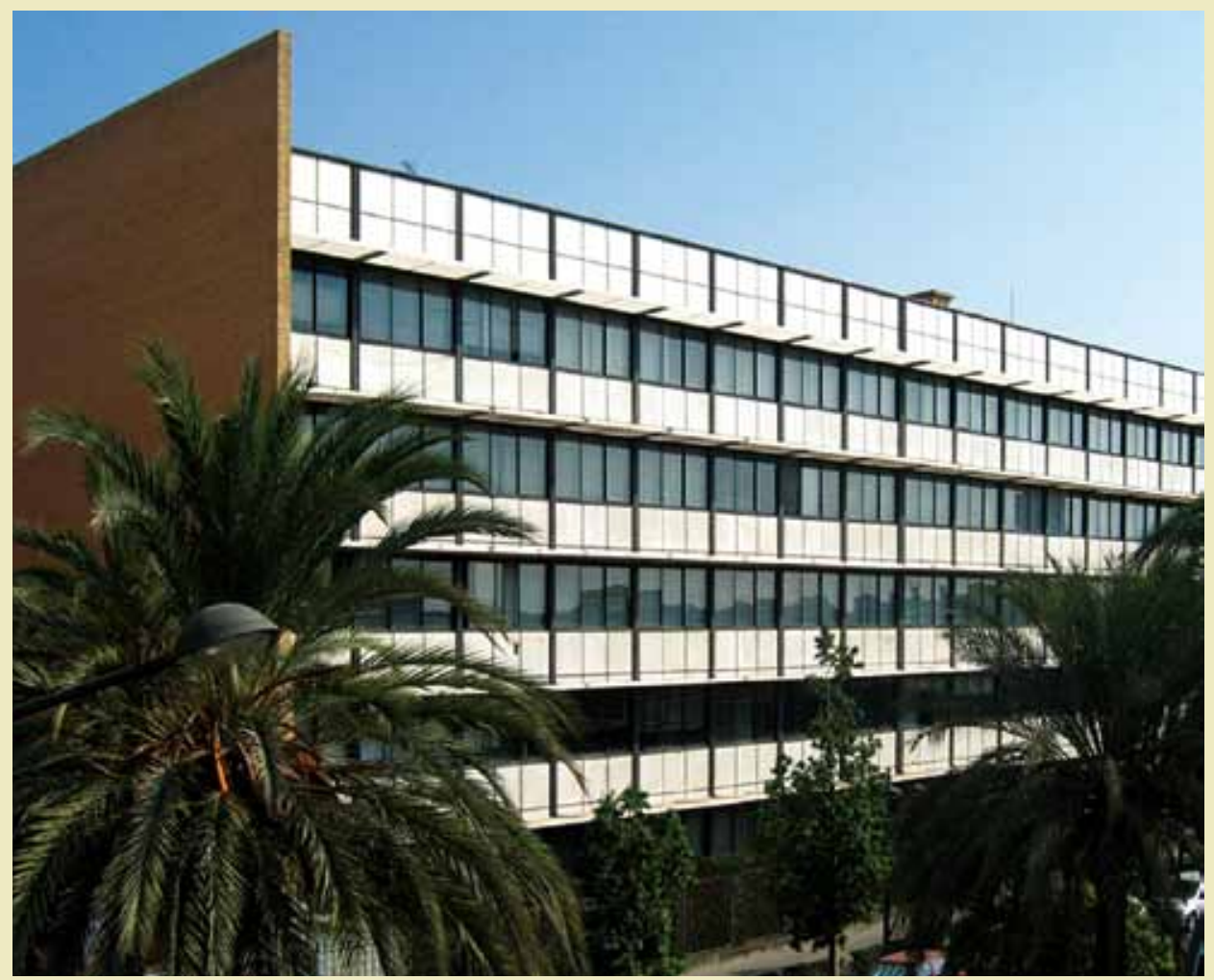

\section{RESUMEN}

Se realiza una aproximación a la evolución de la arquitectura docente valenciana desde el inicio de la II República en 193 I y a través de los diferentes acontecimientos políticos que se suceden en España hasta reconocer diferentes períodos que no sólo marcaron a la arquitectura sino a toda una sociedad que se formaba bajo su influencia.

Se seleccionan tres obras paradigmáticas de la arquitectura docente valenciana, se hace un breve recorrido por el (los) autor(es), por las condiciones bajo las que se llevó a cabo el encargo, el tipo de escuela, la localización y el estado actual, que permiten un acercamiento independiente a cada obra.

Finalmente, se intenta demostrar la validez actual de los valores modernos en la arquitectura docente de finales de los cincuenta a través del análisis comparativo de los tres colegios coetáneos: el Guadalaviar, el Alemán y la Pureza, de donde se obtienen las claves fundamentales que desarrolló su arquitectura.

\section{Palabras clave}

Arquitectura valenciana, arquitectura docente, modernidad. 


\section{PARADIGMATIC SCHOOLS OF THE MODERN VALENCIAN ARCHITECTURE}

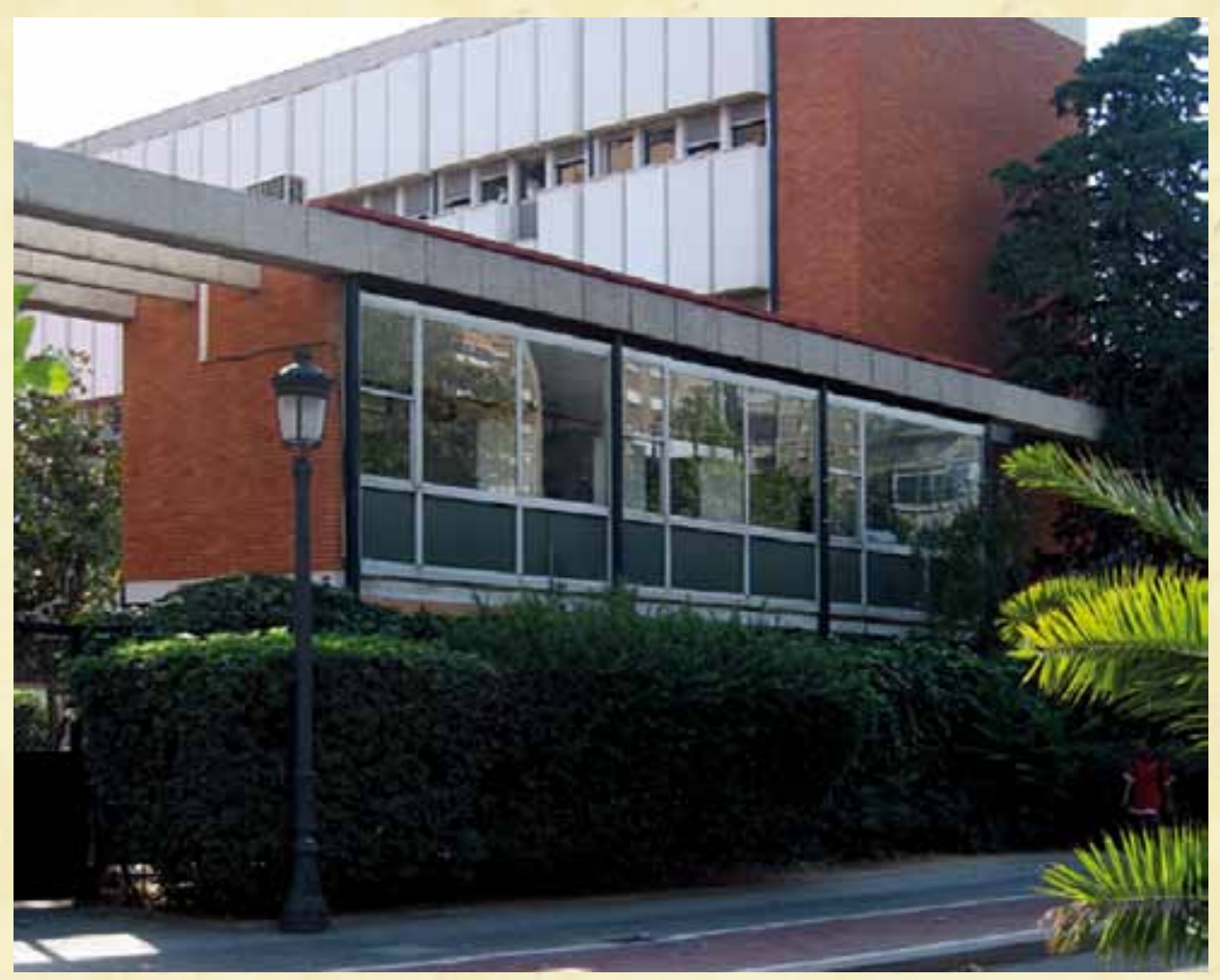

Madrid, 1978. Arquitecta en 2005 por la ETSAV-UPV. Becaria del Departamento de Proyectos Arquitectónicos, 2003-2006. ETSAV-UPV. Máster Oficial "Teoría y Práctica del Proyecto de Arquitectura", 20062007. ETSAB-UPC. Actualmente realiza el doctorado en "Proyectos Arquitectónicos" en la ETSAB-UPC, donde es becaria predoctoral y forma parte del Grupo de Investigación "La Forma Moderna". Desarrolla su experiencia profesional en paralelo a la académica. ETSAVUPV_Escuela Técnica Superior de Arquitectura de Valencia. Universidad Politécnica de Valencia. ETSABUPC_Escuela Técnica Superior de Arquitectura de Barcelona. Universidad Politécnica de Cataluña.

\section{ABSTRACT}

An approach to the evolution of the Valencian educational architecture is realised from the beginning of the II Republic in I93 I and through the different political events that happened in Spain, in order to recognize different periods that not only marked the architecture but a whole society that was formed under its influence.

The research selects three paradigmatic works of the Valencian educational architecture and take a brief tour through the authors, the conditions under which the job was carried out, the type of school, the location and the present state, that allow an independent approach to each work.

Finally, the intention is to demonstrate the present validity of the modern values in the educational architecture of final years of the fifties through comparative analysis of the three contemporary schools: the Guadalaviar, the Aleman and the Pureza, from where can be obtained the fundamental keys that developed its architecture.

\section{Keywords}

Valencian architecture, Educational architecture, modernity 


\section{INTRODUCCIÓN}

I El artículo parte del texto "Valores modernos en la arquitectura docente. Valencia, tres colegios: Guadalaviar, Alemán y Pureza". Tesina defendida en octubre de 2007 en el Máster Oficial "Teoría y Práctica del Proyecto de Arquitectura" dentro del Programa de Postgrado que desarrolla el Departamento de Proyectos Arquitectónicos de la Escuela Técnica Superior de Arquitectura de Barcelona. (ETSAB-UPC.)

2 La elección de las obras viene apoyada por tres publicaciones:

"Arquitectura del Movimiento Moderno. Registro Docomomo Ibérico. 1925-1965" de 1996 que sitúa a dos de los colegios seleccionados (el Colegio Pureza queda excluido) al lado de otros edificios docentes de ámbito nacional como La Facultad de Derecho (1958) en Barcelona de G. Giráldez, P.L. Iñigo y X. Subías, el Gimnasio del Colegio Maravillas (196I) en Madrid de A. de la Sota o la Facultad de Derecho (1958-67) en Valencia de F. Moreno Barberá, entre otros.

La exposición itinerante, con su catálogo correspondiente, “20x20. Siglo XX Veinte obras de arquitectura moderna", patrocinada por la Comunidad Valenciana y ampliamente difundida entre 1997 y 2003, junto a "Registro de arquitectura del siglo XX. Comunidad Valenciana", editado en 2002, que recogen las obras más destacadas de la arquitectura de la Comunidad Valenciana que incluye los tres edificios.
En la segunda década de los cincuenta se produjo, en España, una gran proliferación de construcciones escolares debido al aumento de las escolarizaciones y a las esperanzas de evolución hacia una sociedad renovada y culturalmente formada que fomentaba la apertura de nuevos centros docentes. Este hecho, unido a la recuperación de una segunda modernidad por parte de los arquitectos españoles, propició que la arquitectura docente experimentase una verdadera renovación.

Bajo estas premisas, y como telón de fondo la ciudad de Valencia, se pretende demostrar la validez actual de los planteamientos establecidos en tres colegios coetáneos, que supusieron una gran innovación en su época.

Las tres obras seleccionadas ${ }^{2}$ son consideradas piezas imprescindibles para entender el proceso de la renovación disciplinar en el caso particular de Valencia, a partir de la visión concreta entorno a la arquitectura docente. (Ver foto 1)

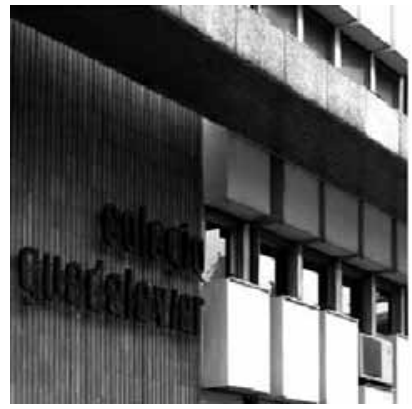

Foto 1. Colegio Guadalaviar

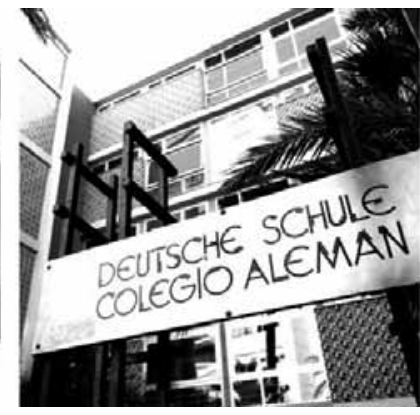

Foto 2. Colegio Alemán de 1959

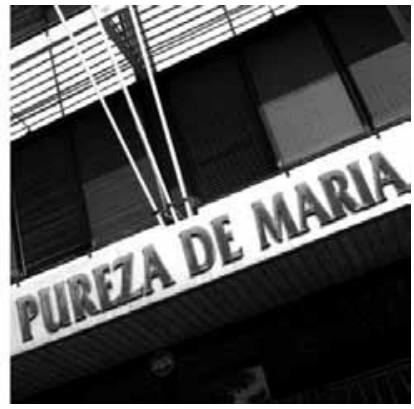

Foto 3. Colegio Pureza de María
El Colegio Guadalaviar de 1958 del arquitecto Fernando Martínez García-Ordóñez, quien con ésta su opera prima, supo expresar en su construcción la influencia de la vertiente californiana del movimiento moderno.

El Colegio Alemán de 1959 de los arquitectos Pablo Navarro Alvargonzález y Julio Trullenque Sanjuán, quienes bajo la supervisión de la Bundesbaudirektion de Berlín y en colaboración con los arquitectos alemanes E. Becker y D. Weise, desarrollaron las ideas que empezaron a germinar con el espíritu de la Bauhaus en Alemania.

El Colegio Pureza de María de 1962 del arquitecto Mauro Lleó Serret, quien supo aproximarse a la arquitectura moderna a través de la sinceridad constructiva como método y de la corrección como disciplina compositiva.

La mirada hacia la arquitectura de décadas anteriores pretende invitar a la reflexión y desde el acercamiento a las obras entresacar su cuota de vigencia. Se parte de la creencia que la experiencia moderna tiene validez hoy en día más allá de actuaciones basadas en una intencionalidad meramente contemporánea y en ocasiones efímera, y en que la recuperación de un cierto entendimiento del oficio del arquitecto se basa en un continuo proceso de formación. 


\section{APROXIMACIÓN A LA ARQUITECTURA DOCENTE VALENCIANA. 1931-1965}

\section{I93 I-36_La escuela como símbolo del progreso. La república}

La actual Comunidad Valenciana recibió, con considerable retraso respecto a Madrid y Barcelona y ya con el inicio en 193I de la II República, el impulso hacia una nueva mo dernidad arquitectónica y urbanística, condicionada por los nuevos valores inexcusables de una sociedad renovada (salubridad, consumo, culto al cuerpo y a la salud), y por nuevos materiales y técnicas constructivas.

El planteamiento de la escolarización real para toda la población en edad escolar marca la gestión de la construcción de edificios escolares en todo el ámbito español, basándose en las intenciones republicanas que "el nivel de formación de un pueblo era un bien que garantizaba el progreso". 3

Bajo este impulso republicano se llevó a cabo un ambicioso Plan Escolar para la realización de colegios públicos y laicos con el que se realizaron un gran número de edificios educativos que fueron proyectados y construidos por todos los municipios valencianos y en las barriadas de las capitales.

Las escuelas se plantean bajo los principios de la arquitectura funcionalista como una yuxtaposición de aulas en las que se busca la buena orientación, iluminación y ventilación, así como la relación con los espacios comunes y el entorno que le rodea.

Como obras de referencia en la arquitectura de la República y de la arquitectura valenciana de vanguardia cabe destacar como ejemplo de edificio docente las Escuelas Graduadas en Rocafort (1 932) de A. Baeschlin. (Ver foto 4)

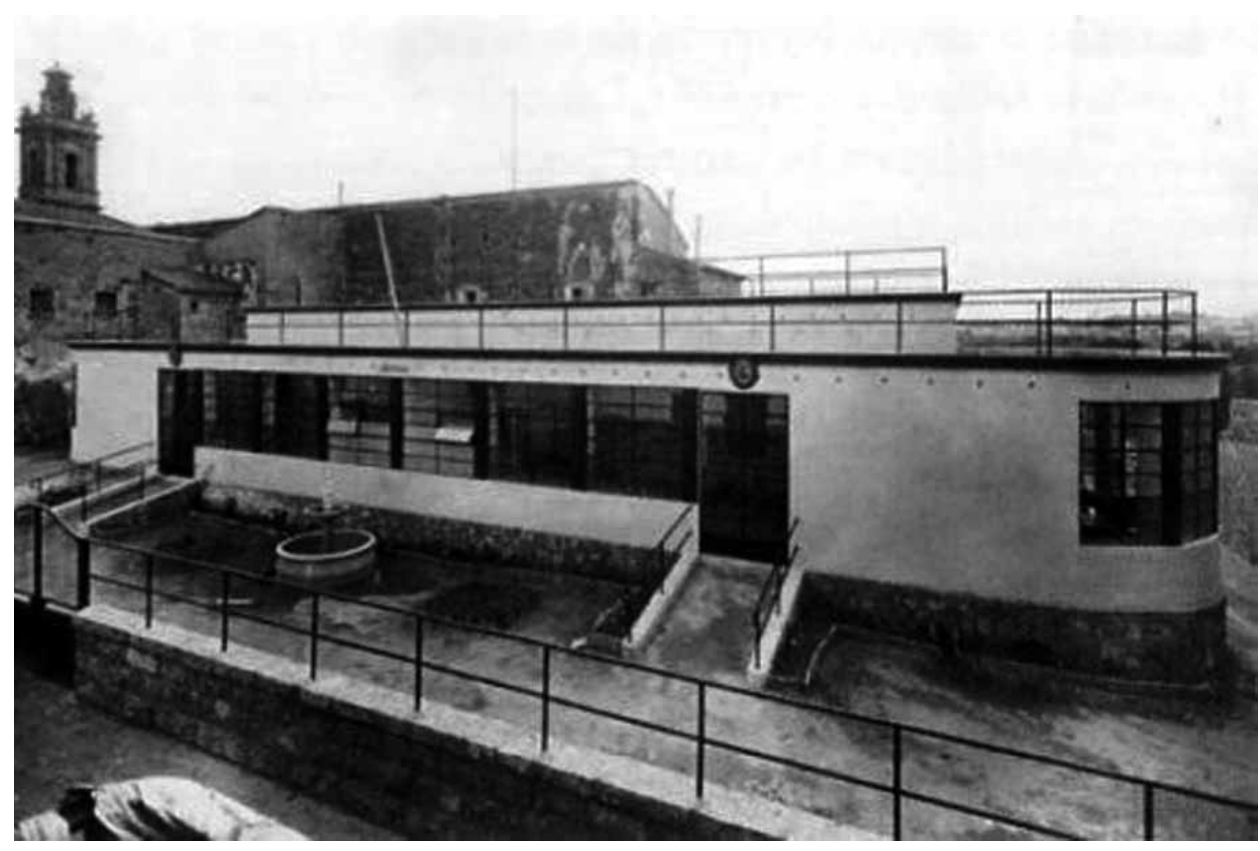

3 Martínez Medina, Andrés. Registro de Arquitectura del s.XX. Artículo: "Aquella década revolucionaria: las ciudades valencianas durante la II República (1930-39)". 


\section{6-39_La escuela como una necesidad de superficie. La guerra civil}

Durante el periodo de guerra la escuela surge como una necesidad de superficie en el que además de los edificios escolares existentes, se adoptan para uso escolar un gran número de edificios construidos para otros usos.

\section{9-57_La escuela privada. Inmovilismo y restauración. La posguerra}

Aunque la posguerra es de un inmovilismo total en el campo de las construcciones escolares, durante los primeros años se restauran las escuelas públicas afectadas por la guerra y se propone la escuela privada como garantía de la educación. Los edificios escolares que se construyen de nueva planta retoman planteamientos, cuyos recursos formales remiten a una arquitectura casticista de matices clásicos, cuya máxima expresión fueron las escuelas graduadas ancladas en planteamientos historicistas y que quedan claramente ejemplarizados en Valencia en proyectos como el Colegio del Loreto (1940) de L. Albert Ballesteros (Ver Foto 5) o el Colegio Jesús y María (1952) de A. Borrell Sensat.

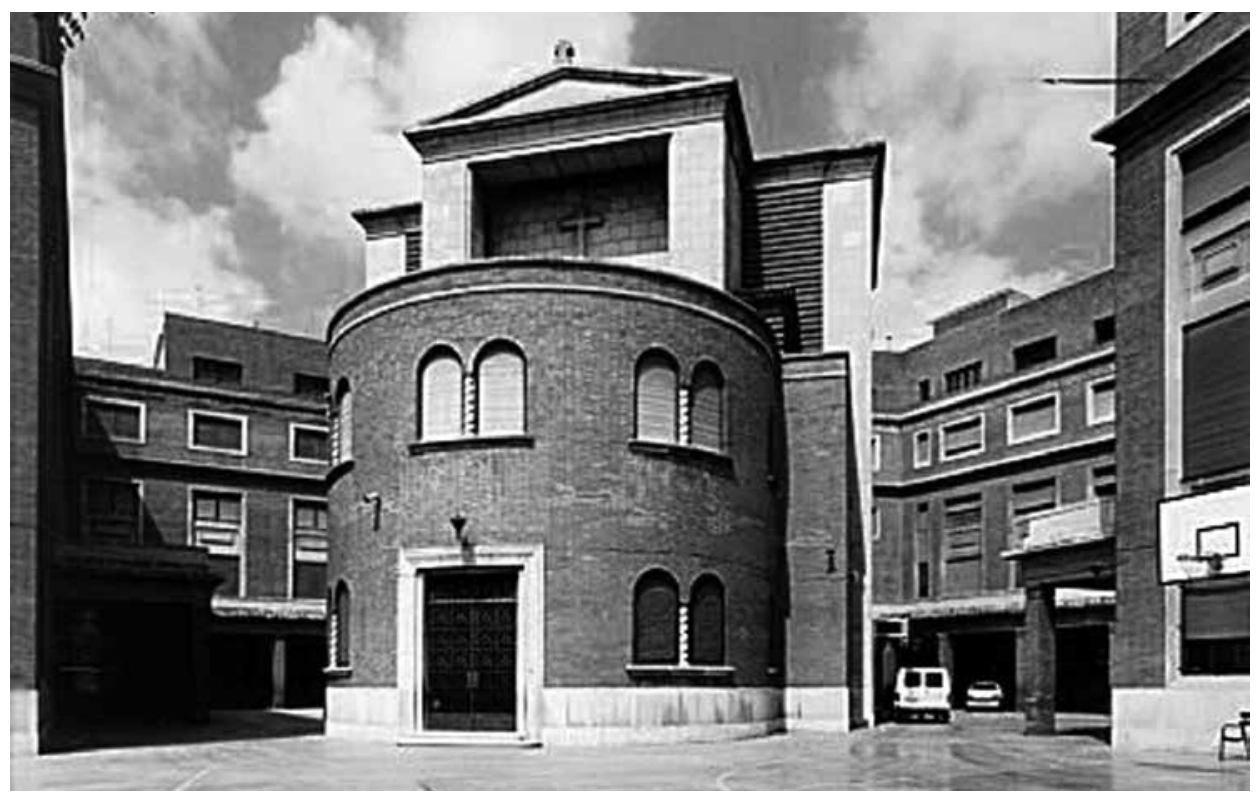

Foto 5. El Colegio Jesús y María (1952) de A. Borrell Sensat.

En 1949 tiene lugar la $\vee$ Asamblea Nacional de Arquitectos con tres sedes (Barcelona, Palma de Mallorca y Valencia), en la que la visión de la realidad arquitectónica de la exposición provocará la transición entre las viejas y las nuevas ideas, pues siembra el panorama para la recepción de una segunda modernidad de la arquitectura española, pero que tendría lugar años más tarde, en la segunda década de los cincuenta.

En el caso particular de Valencia también surgen las primeras reacciones frente al estancamiento cultural del régimen con las exposiciones del Grupo Z en 1947, el Grupo Los Siete en 1949 y la primera muestra de Eusebio Sempere en 1949.

El comienzo del fin de la autarquía en España se produce a principios de los cincuenta con el ingreso en la UNESCO en 1952 y en la ONU en 1955, iniciándose así una apertura 
económica hacia el exterior, que pondrá en marcha un proceso de recuperación de las actividades de preguerra. Esta apertura permitiría a los arquitectos conciliar técnica y arquitectura moderna, tanto por la recepción de nuevos materiales como por la mejora de la producción industrial. Las referencias internacionales llegan con cuenta gotas y las revistas de mayor difusión como la Revista Nacional de Arquitectura publican por primera vez un artículo de Le Corbusier en 195I, sobre Richard Neutra uno en 1953 y otro en 1955 y de Mies no se publicaría hasta 1957, pero de una obra muy inicial, el pabellón de Barcelona de 1929. Bajo este panorama, los arquitectos más preocupados, buscan en publicaciones extranjeras los referentes a la arquitectura moderna y en particular a la que se realiza en Norteamérica.

\section{7-65_La nueva escuela. Fin de la autarquía}

Es en la segunda década de los cincuenta cuando se produce en el país un reencuentro con una arquitectura portadora de los principios modernos de una nueva época en la que se habían superado las crisis producidas por la Guerra Civil Española y la II Guerra Mundial. Los arquitectos formados tras la guerra civil recuperan como referencia a los maestros de preguerra como Le Corbusier, Mies, Gropius o Mendelshon y a nuevos protagonistas como Neutra, Niemeyer, Breuer o Saarinen.

En Valencia se crea, en 1956, el Movimiento Artístico del Mediterráneo y en 1957 el Grupo Parpalló ${ }^{4}$, formado por artistas como Juan Genovés, Michavila o Andreu Alfaro y arquitectos como Pablo Navarro Alvargonzález y Juan José Estellés, que transmitirán a través de la revista Arte Vivo los propósitos e intenciones del grupo, basados en la cooperación interdisciplinar y en la integración de las artes.

La particular situación que supone para Valencia en 1957 la trágica riada del Río Turia acelerará la realización del proyecto de ordenación territorial más ambicioso del siglo en el área metropolitana de la ciudad de Valencia. Entre otras actuaciones se llevan a cabo la construcción de nuevas instituciones públicas y escolares y se define la expansión de la ciudad universitaria con edificios como la Facultad de Derecho (1 959) (Ver foto 6) o la Escuela de Ingenieros Agrónomos (1958-67), ambas de F. Moreno Barberá.

Foto 6. La Escuela de Ingenieros Agrónomos (1958-67), ambas de F. Moreno Barberá

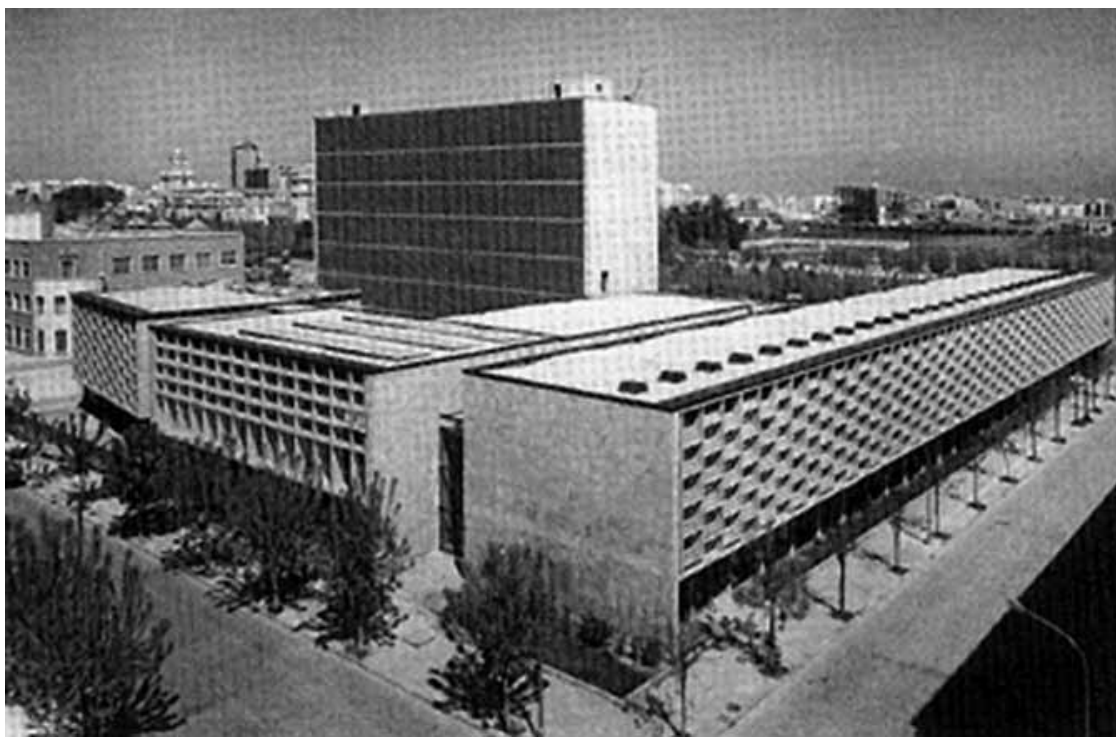

4 Grupo Parpalló: Se constituye en Valencia en 1956. El grupo es fundado para conectar la creación artística valenciana con el panorama internacional tras la interrupción causada por la Guerra Civil. Editan la revista Arte Vivo, concebida como publicación periódica de la que aparecieron sólo cuatro números, todos ellos de enorme interés para la compresión del arte español del momento. 
Al centrar la atención en la arquitectura docente que surge a finales de los cincuenta y que se desarrollará durante la siguiente década, aparece una doble vertiente:

Por un lado, los Grupos Escolares del Plan Riada (1957-60) realizados a partir de un Concurso del Ministerio de Educación Nacional y el Ayuntamiento de Valencia para intentar resolver la problemática situación tras el desbordamiento del Turia, que dejó a la ciudad de Valencia con 12.000 niños sin escuelas. Este concurso dio como resultado la definición de prototipos de grupos escolares que planteaban un avance respecto a la arquitectura docente de posguerra y retomaba los planteamientos iniciados en la República basados en la repetición, la economía y la higiene. Se construyeron edificios escolares en lugares estratégicos de expansión de la ciudad, de lenguaje sencillo pero con planteamientos funcionales y modernos. Sin embargo, muchos de ellos han sido alterados de manera puntual, mientras otros han sufrido radicales modificaciones. Entre otros colegios realizados por J. J. Estellés, José Pedrós y J. García Matarredona, cabría destacar el Colegio Primer Marqués del Turia (1958) (Ver foto 7) o el Colegio Ausias March (1958) de los arquitectos R. Fernández Huidoloro y P. Pintado Riba.

Foto 7. el Colegio Ausias March (1958) de los arquitectos $R$. Fernández Huidoloro y $P$. Pintado Riba.

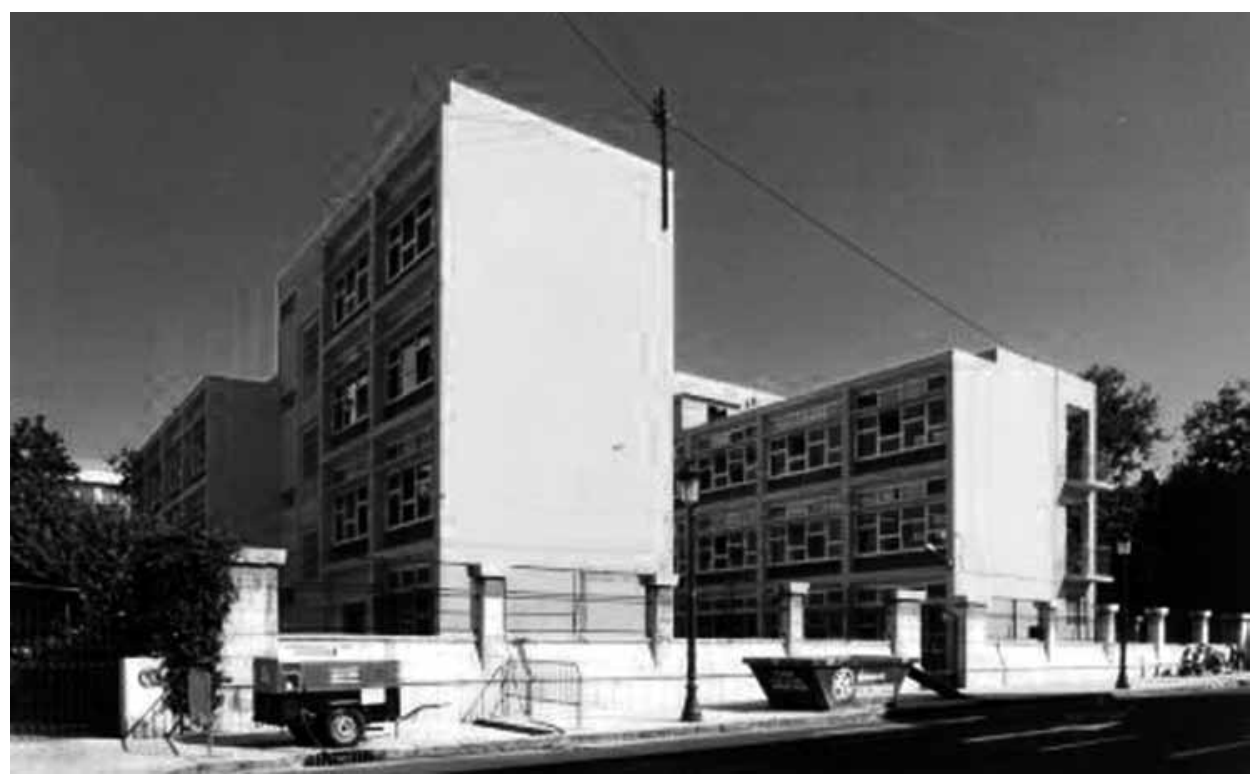

Por otro lado y, acogiéndose en algunos casos al plan especial de ayudas, unido a la posibilidad económica que brindaba la iniciativa privada y junto a la nueva estructura de ordenación en determinadas áreas de la ciudad a través de grandes manzanas definidas por construcciones en edificación abierta y amplios espacios libres y ajardinados posibilitó el llevar a cabo un gran número de centros docentes de gran calidad arquitectónica.

Estos proyectos se construyeron basándose en la utilización de nuevos materiales, en la industrialización y la prefabricación, en la honestidad constructiva y técnica, en la expresividad de las protecciones solares o en el tratamiento del hormigón armado visto y su texturización.

Entre los ejemplos de este período destacan edificios como las Escuelas Profesionales San José ( 1962) de C. Borso di Carminati González y R. Contel Comenge (Ver Foto 8), el Instituto Sorolla (1 964) de J. R. Aspiazu Ordóñez, junto a tres colegios 
de iniciativa privada, considerados los más relevantes de la época en materia escolar y que se explican a continuación.

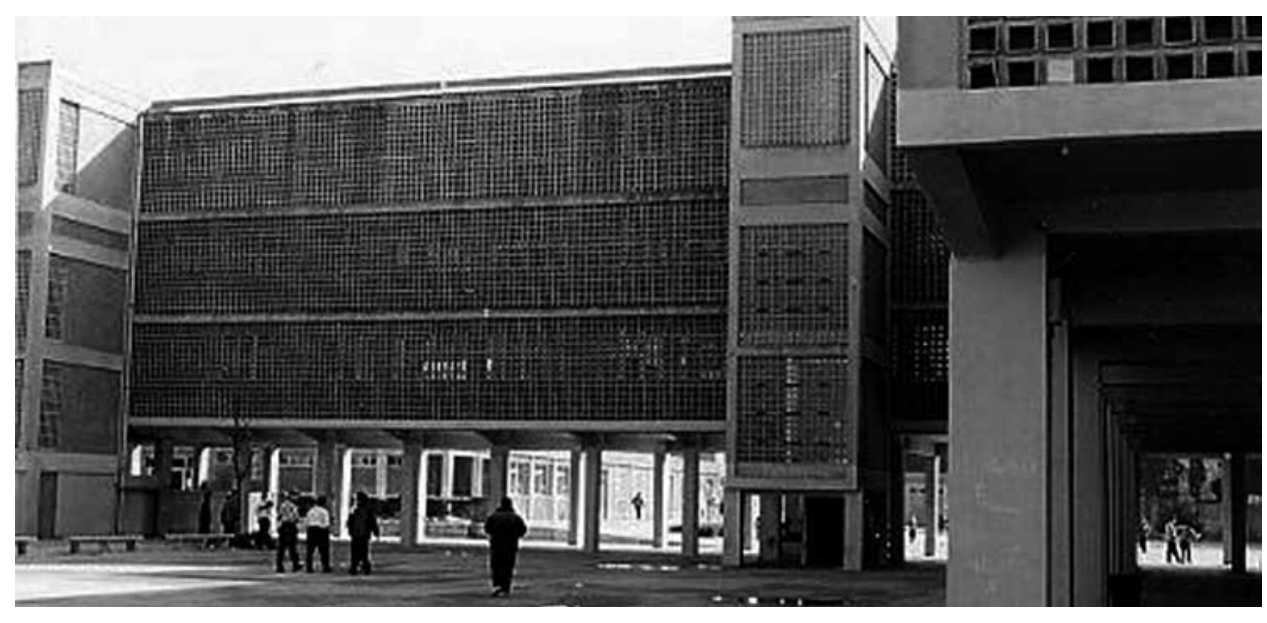

\section{COLEGIO GUADALAVIAR}

El Colegio Guadalaviar (Ver Foto 9) fue proyectado entre 1957-58 y construido entre 195960 y es la "opera prima" del arquitecto asturiano Fernando Martínez García-Ordóñez (Salas, Asturias 1922) formado en Madrid. Tras obtener el título en 1955 se trasladó a Valencia para formar parte como miembro asesor del Plan Sur. En 1960 formó el estudio profesional GO-DB Arquitectos junto a Juan María Dexeus Beatty, con quien realizó importantes estudios y trabajos en el ámbito de la prefabricación y la industrialización, y realizaron importantes aportaciones a la arquitectura valenciana de la $2^{\mathrm{a}}$ mitad del siglo $\mathrm{XX}$.

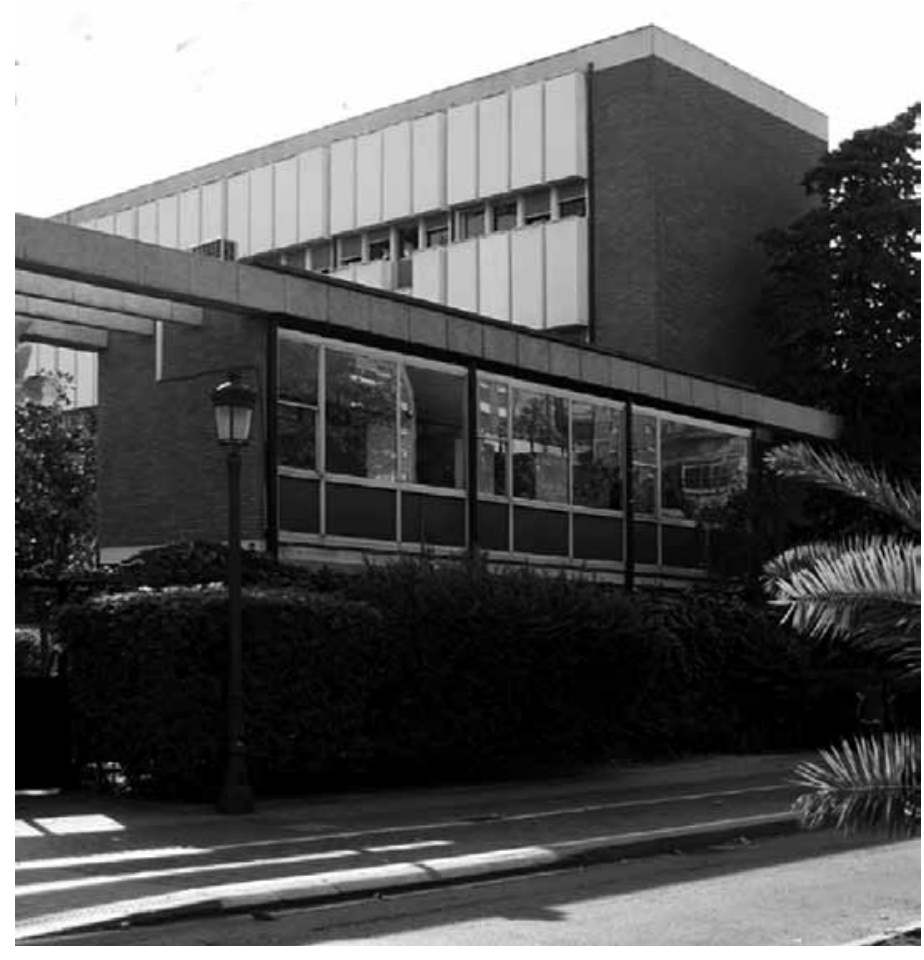

Foto 8. El Instituto Sorolla (1964) de J. R. Aspiazu Ordóñez, 
Recientemente ha sido premiado con la distinción de Mestre Valenciá d’Arquitectura.

Entre sus obras más relevantes se encuentran el Conjunto de viviendas Cadahia (1963) en Valencia, la Fundación Borrás Estela (1966) en Beniarjó y la Parroquia del Mar (1967) en Jávea, que fue galardonada como Premio Nacional de Arquitectura en 1969.

El edificio fue publicado en diversas revistas españolas especializadas de la época, como Informes de la Construcción y Cuadernos de Arquitectura y Urbanismo y en otras publicaciones a nivel internacional como "l'Architecture d'Aujourd'hui" (le dedicó un reportaje que concluía con la frase: "école de grande qualité") y "The Architect \& Building News". Incluido desde 1996 en el registro Docomomo Ibérico, ha sido recientemente presentado al registro Docomomo Internacional.

Acogiéndose al plan especial de ayudas del Plan Riada de 1957, la sociedad Construcciones Escolares S.L. encargó a García-Ordóñez, el proyecto de construir una Escuela-Jardín de infancia.

Se trata de una Escuela-jardín de infancia de iniciativa privada, vinculada al Opus Dei, con cuatro aulas de primaria con capacidad para 120 alumnas y cuatro aulas de infantil para unas 80 alumnas. Además, resuelve una residencia de profesoras con capacidad para 10 profesoras.

El edificio se construye en un terreno llano de forma trapezoidal de aproximadamente $3.320 \mathrm{~m}^{2}$, situado en la confluencia de dos importantes avenidas, la actual Avenida de Blasco Ibáñez y la Avenida de Aragón, y que en el momento en que fue proyectado, venía delimitado en su parte Este por la tapia del ferrocarril de Valencia a Aragón. La parcela se regularizó en 1974 con la apertura de la Avenida de Aragón y la desaparición de la línea de ferrocarril, lo que amplió su superficie a $6.235 \mathrm{~m}^{2}$. Actualmente se encuentra rodeado de torres residenciales. (Ver Foto 10)

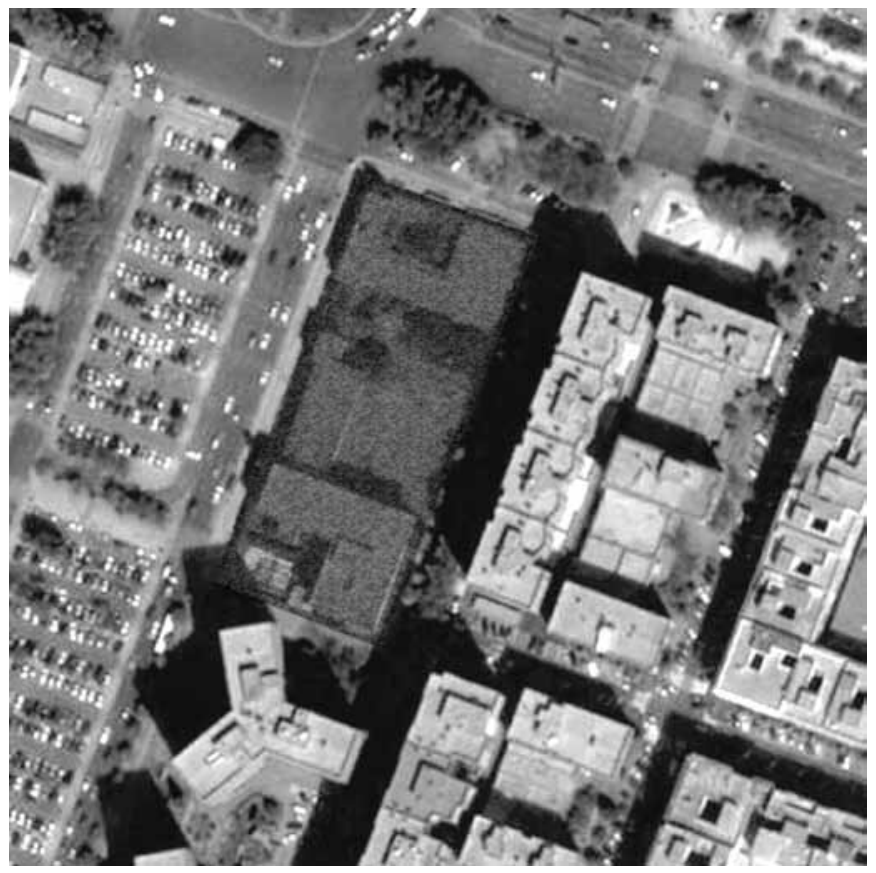


El conjunto de las edificaciones ha sufrido diversas reformas y ampliaciones (1964, 1968, $1972, \ldots)$ que desfiguran la imagen original, pese a estar avaladas por el propio arquitecto.

\section{COLEGIO ALEMÁN}

El Colegio Alemán (Ver Foto II) proyectado entre 1958-59 y construido entre 1959-6 I es obra de los arquitectos valencianos Pablo Navarro Alvargonzález y Julio Trullenque Sanjuán, y fue desarrollado bajo la supervisión de técnicos alemanes (E. Becker y D. Weise). Ambos arquitectos obtuvieron el título por la Escuela de Arquitectura de Madrid en 1952 y desarrollaron sus obras más notables conjuntamente. A partir de mediados de los 60 ambos dedicaron su carrera profesional a la Administración.

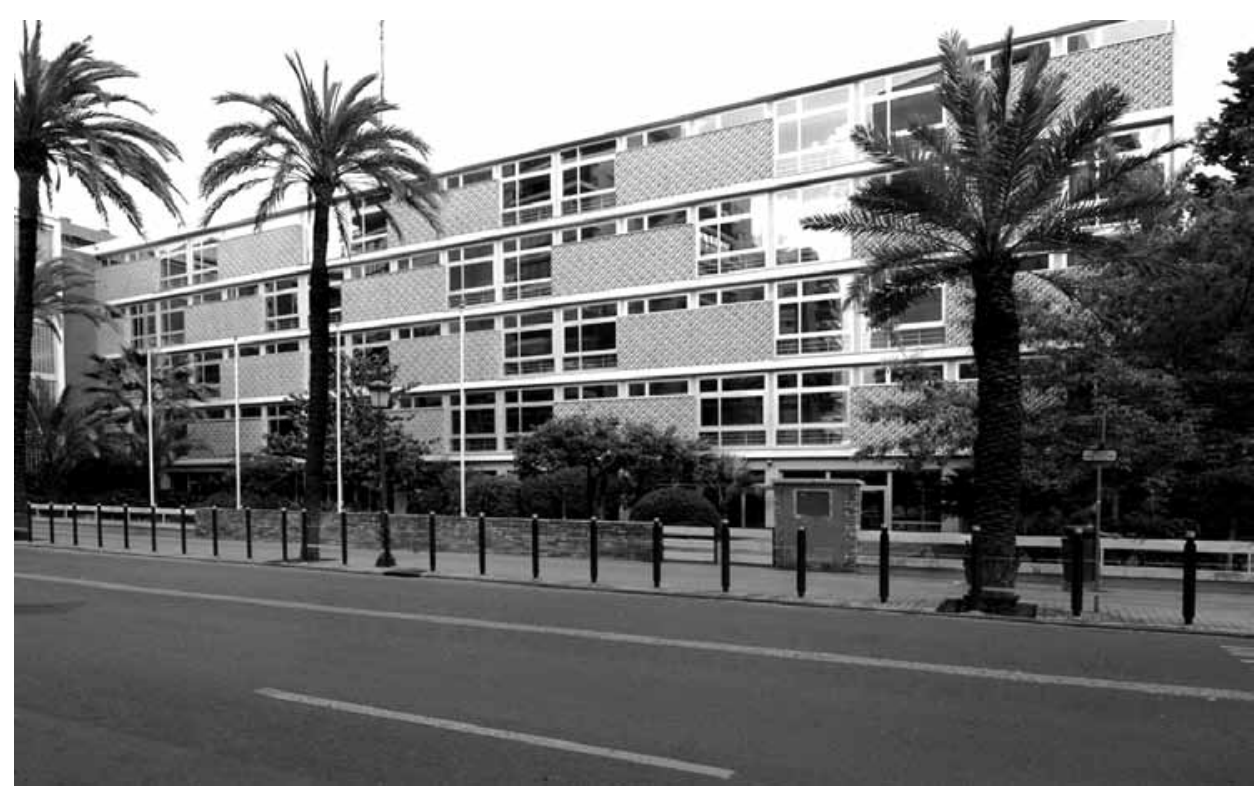

Las referencias de las obras iniciales de ambos arquitectos parten de la incorporación de códigos estilísticos absolutamente modernos. En el caso particular del colegio Alemán, desa rrollaron las ideas que empezaron a germinar con el espíritu de la Bauhaus en Alemania.

Entre sus obras cabría resaltar la Vivienda unifamiliar (1954) en Altea y el Edificio de Agroquímica y Tecnología de los Alimentos (1957) en Valencia.

Antes de su construcción el colegio fue publicado en la revista ARTE VIVO $\left(n^{\circ} 2\right.$, 1959) del Grupo Parpalló, del que formaba parte Pablo Navarro, junto a otros artistas y arquitectos valencianos.

En 196I, el colegio recibió el premio que concedía anualmente el Colegio de Agentes de la Propiedad Inmobiliaria de Valencia y su Provincia.

Incluido desde 1996 en el registro Docomomo Ibérico, ha sido recientemente presentado al registro Docomomo Internacional. 
5 Es decir, "construcciones aisladas sin medianeras, donde el jardín o zona verde deberá ocupar gran parte de la superficie". (Navarro Alvar-González, Pablo. Arte Vivo $\left.\mathrm{n}^{\circ} 2\right)$
Foto 12. La parcela del Colegio Alemán Ortofoto
La República Federal Alemana, para la Asociación Cultural en pro del Colegio Alemán, y bajo la supervisión de la Bundesbaudirektion de Berlín, encargó a los arquitectos valencianos la colaboración para la redacción del proyecto y dirección de obras del Colegio Alemán de Valencia. La elección del solar vino condicionada por la posibilidad que ofrecía de construirse mediante "edificación abierta". 5

Se trata de un Colegio mixto privado, de docencia y dirección alemana, que desarrolla la educación infantil, primaria y secundaria para un total de 600 alumnos.

Incorporaron, fieles al ideal de integración de las diversas disciplinas artísticas, una escultura aerodinámica de Andreu Alfaro en el patio y un mural interior realizado por Heinrich Schwarz.

El edificio se sitúa en un terreno sensiblemente plano, ocupa una manzana completa de forma rectangular de aproximadamente $8.000 \mathrm{~m}^{2}$ de superficie. Actualmente la parcela cuenta con $14.200 \mathrm{~m}^{2}$, la edificación se encuentra rodeada de altas edificaciones residenciales. (Ver Foto 12)

El colegio Alemán ha sufrido diversas modificaciones desde su construcción, aunque sin perjudicar excesivamente al conjunto.

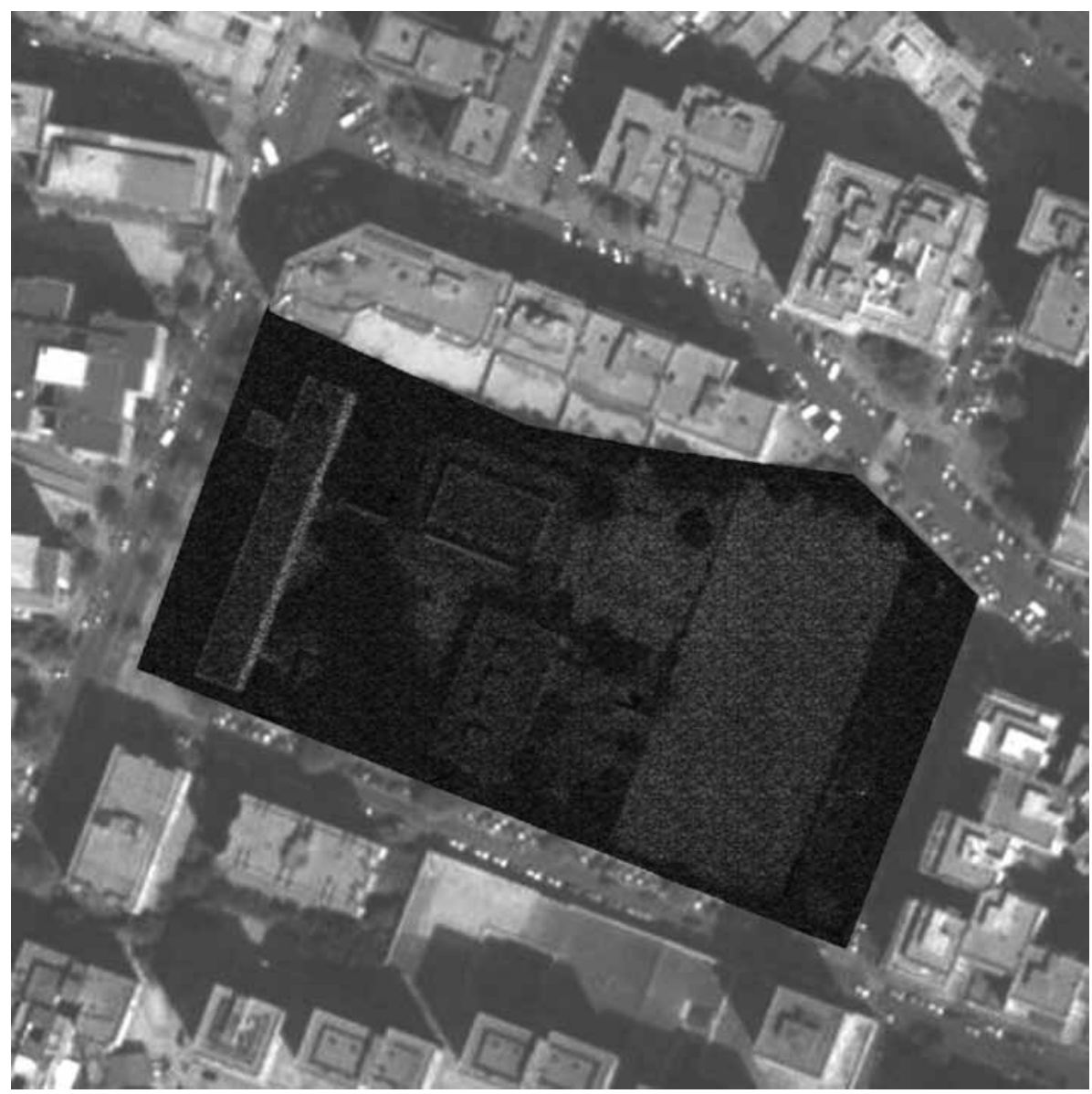




\section{COLEGIO PUREZA DE MARÍA}

El Colegio Pureza de María (Ver foto 13) fue proyectado en dos fases iniciándose en 1962 con el parvulario y llevándose a cabo la construcción entre 1963-65. Es obra de Mauro Lleó Serret (19|4-200I), arquitecto valenciano quien al iniciar su actividad profesional, recién acabada la Guerra Civil, supo aproximarse a la arquitectura moderna a través de la sinceridad constructiva como método y de la corrección como disciplina compositiva. Sus influencias provienen de la arquitectura de Mies y Le Corbusier. Su arquitectura supondrá un punto de referencia de recuperación de la modernidad en Valencia desde finales de los cincuenta.

Entre sus obras más relevantes se encuentran la Filial SEAT (1963) y el Colegio Javerianas (1967) ambas en la ciudad de Valencia.

El conjunto escolar fue encargado en dos fases consecutivas por la Orden Religiosa Pureza de María. Se inició con la construcción del pabellón de parvulario y en fase consecutiva se realizó la construcción del edificio principal. Uno de los puntos de partida exigidos por la Orden, fue la de establecer recorridos independientes entre el centro docente y la zona de residencia.

La obra desarrolla un programa docente propio d e un centro religioso y contempla además, el alojamiento para la comunidad de monjas que lo dirigen. El colegio, en origen exclusivamente femenino, cuenta actualmente con unos mil alumnos.

El centro escolar se sitúa en una parcela aislada de forma irregular de aproximadamente II. $200 \mathrm{~m}^{2}$ de superficie, emplazado junto a uno de los accesos más importantes de la ciudad de Valencia en su conexión a la salida de Madrid, la actual Avenida del Cid. (Ver foto 14)

El conjunto de las edificaciones conserva en gran medida el estado original del proyecto.

Foto 13. El Colegio Pureza de María

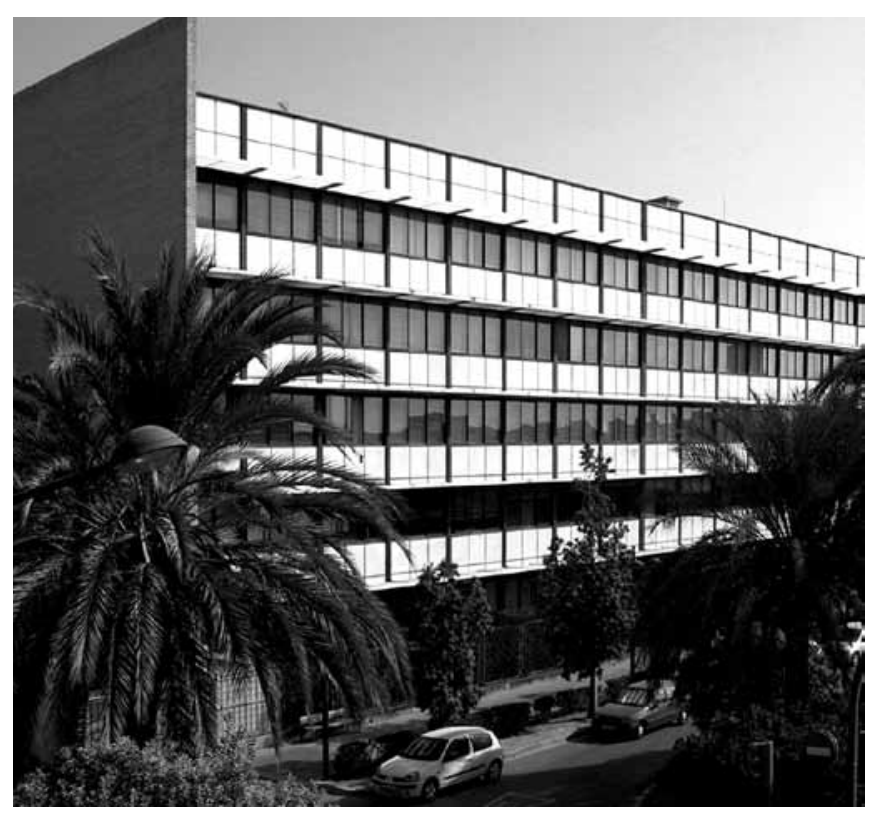

Foto 14. Localización sobre Av. del Cid

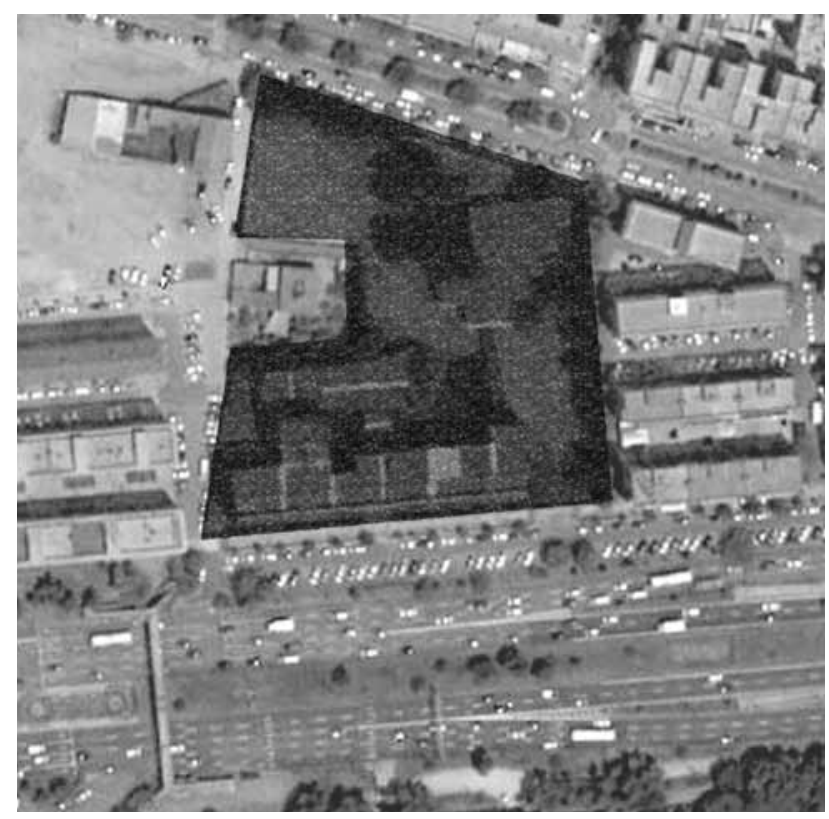




\section{ANÁLISIS COMPARATIVO}

El estudio de los mecanismos proyectuales utilizados contribuye de manera decisiva a la definición del lenguaje moderno en cada uno de los edificios, tanto por la simplicidad de su arquitectura que permite un mayor grado de libertad en su utilización, como por la búsqueda de edificios adaptados a la escala del niño.

\section{IMPLANTACIÓN EN EL SOLAR. ORGANIZACIÓN DE LOS VOLÚMENES}

(Ver Figuras I, 2, 3)

Los tres conjuntos escolares se situaron en zonas de expansión de la ciudad con una clara ordenación de edificación abierta, lo que permitió trabajar a los diferentes arquitectos con volúmenes exentos e independientes, cuidadosamente dispuestos en función de la visualización del conjunto y de su adecuada proporción.

El colegio Guadalaviar trata de resolver un edificio en esquina sin construir la misma, alineándose a las dos avenidas sobre las que recae, con giros ortogonales y desplazamientos entre las partes que generan espacios exteriores $\mathrm{Da}$ escala al conjunto, un volumen de cuatro alturas, se sitúa en paralelo a la Avenida de Aragón para definir el límite de la parcela.

En los otros dos casos, la actitud es diferente, ya que existe una clara prioridad del frente de fachada respecto a los viales secundarios. Se definen como edificios frontales que se resuelven con la construcción de un contundente volumen prismático retirado del límite

Figura 1.

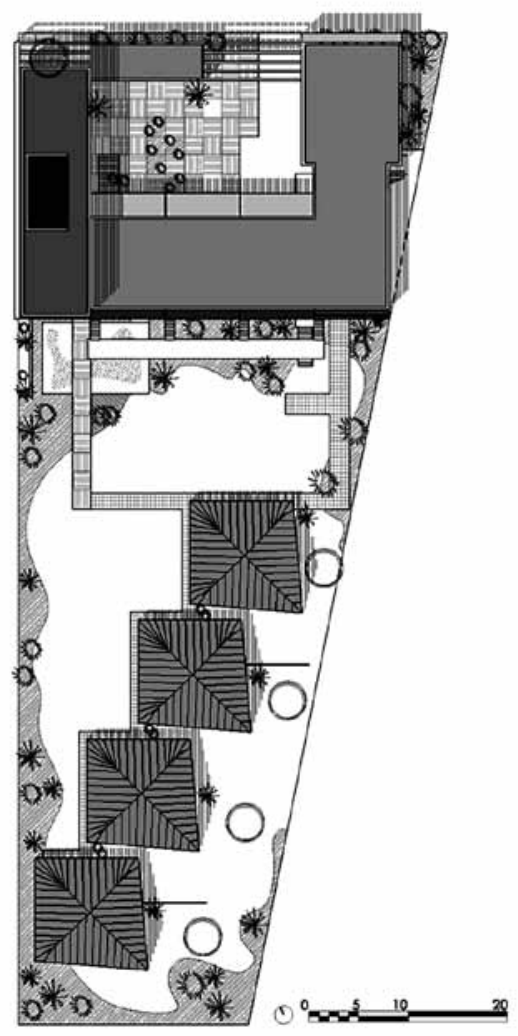

Figura 2.
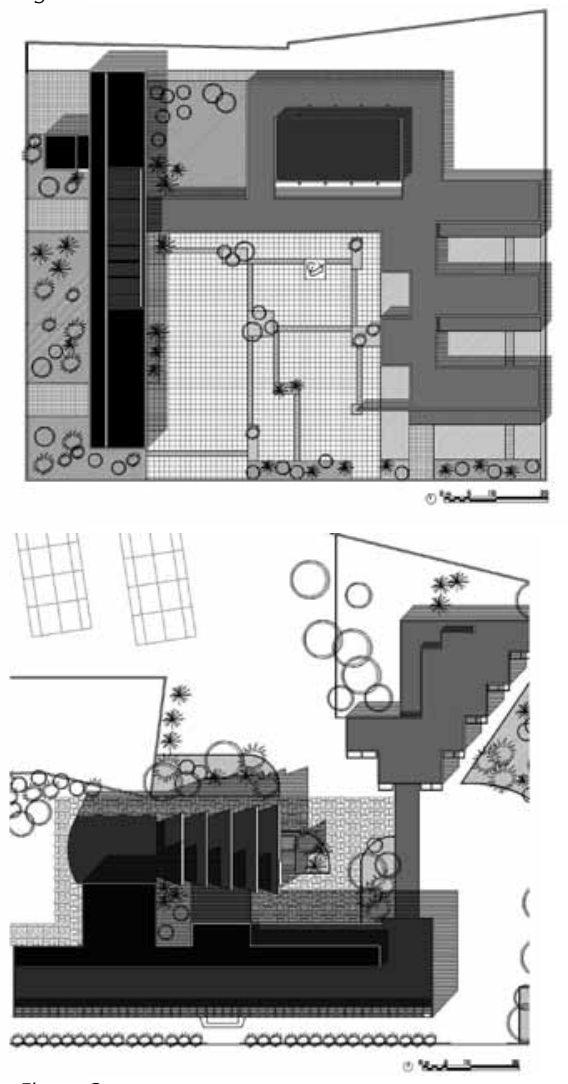

Figura 3. 
de la parcela $12 \mathrm{~m}$ en el Alemán y $6 \mathrm{~m}$ en el caso del Guadalaviar. Tal diferencia de retiro viene provocada por las características particulares del entorno en el que se insertan cada uno de ellos.

Cada proyecto se plantea como una unidad construida a partir de la articulación de distintos fragmentos funcionales: aulas y administración, capilla o gimnasio-salón de actos y pabellones de infantil.

Un aspecto fundamental para la decisión de la organización volumétrica en este tipo de edificios es la orientación que se le debe dar a las aulas para evitar pérdidas de iluminación por la proyección de sombras. En el Guadalaviar y Alemán se consigue además relacionar las aulas hacia los espacios generados al interior de la parcela, con un mayor control visual y acústico.

Los cuerpos principales de los colegios Guadalaviar y Alemán se despegan del suelo para generar áreas cubiertas de acceso o juegos que permitan una mayor continuidad visual de la cota cero.

El Pureza, por el contrario, adquiere una imagen más sólida y pesada, hace juego en se cción con el terreno a través del cuerpo posterior de la Iglesia y el salón de actos en planta semisótano.

Las propuestas de los colegios Alemán y Guadalaviar se desarrollan entorno a un espacio que se puede entender como la evolución del claustro propio de la tipología escolar, pero descentralizado por la asimilación de las premisas modernas. Con este mecanismo de "Patio descentralizado" se construyen unos patios con límites no absolutos, permeables pero no precisos, donde se elimina uno de los frentes construidos.

\section{CONFIGURACIÓN DEL ACCESO. DISEÑO DE LOS ESPACIOS EXTERIORES}

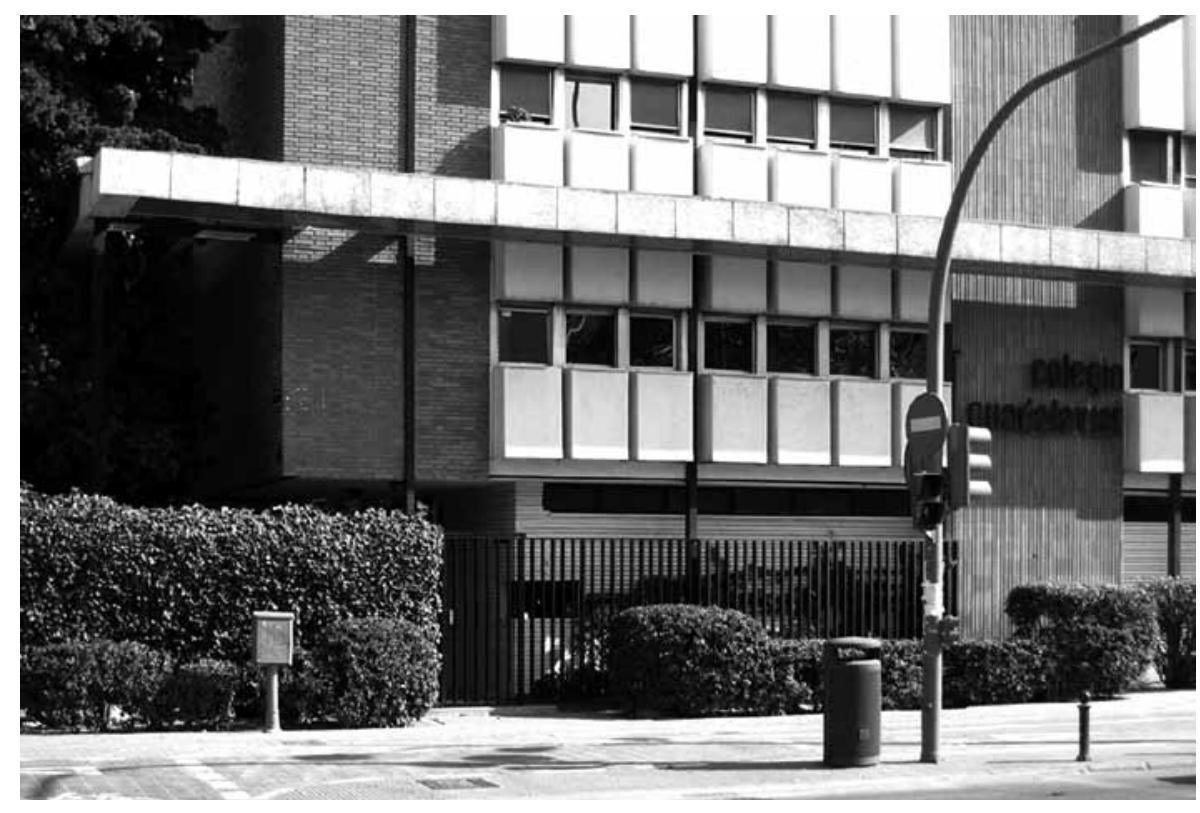




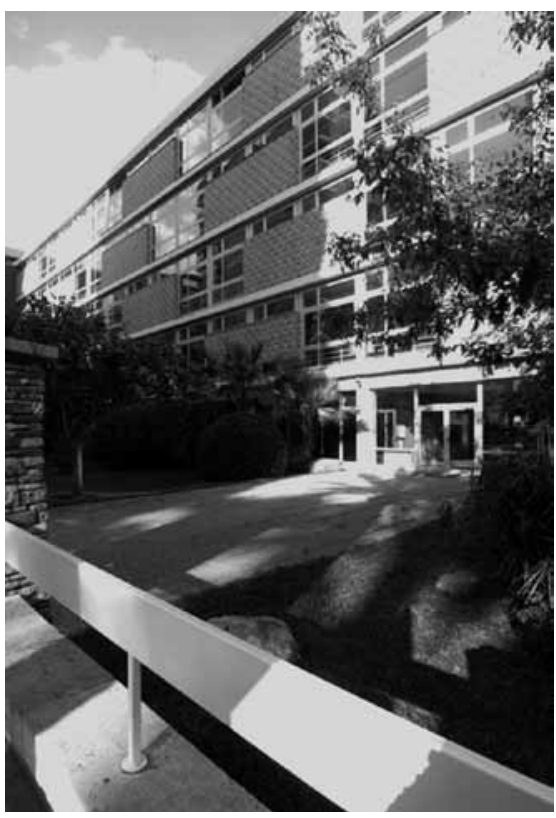

Foto 16. Colegio Guadalaviar

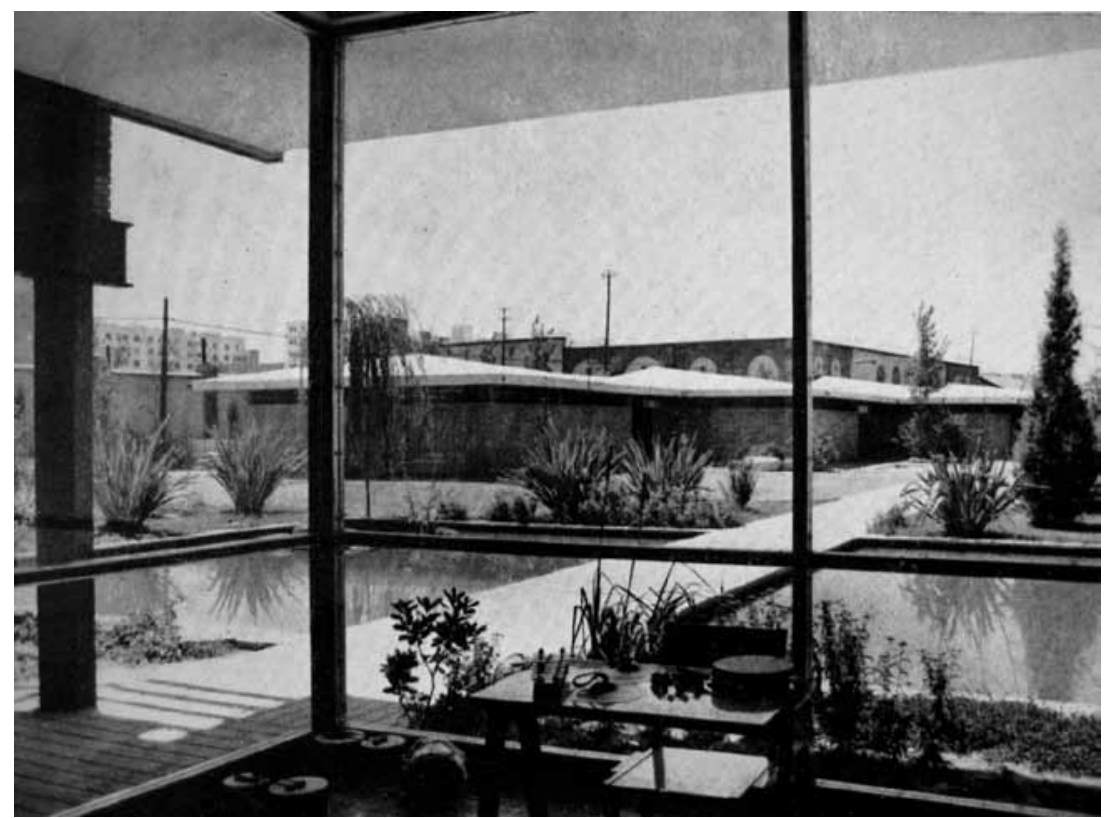

Foto 17. Colegio Alemán

(Ver foto 15, 16, 17)

Una característica común de los tres edificios es la ausencia de monumentalidad en el punto de acceso, si bien la estrategia seguida por cada uno de ellos es diferente.

El acceso principal en el Guadalaviar se produce por debajo del cuerpo de 4 plantas, en posición de esquina. El patio generado al interior revela su funcionalidad como espacio de acogida y de distribución y permite desde él obtener una continuidad espacial al despegar los volúmenes del suelo.

El acceso en el Alemán queda enfatizado por el volumen de la escalera que avanza elocuen temente en perpendicular a la calle. El recorrido se produce en paralelo al mismo a través del jardín que delimita el conjunto hacia el exterior.

La abstracta fachada del Pureza permite situar el acceso al edificio en las dos crujías centrales, marcado por la ausencia de vegetación frente a la valla perimetral y una delgada marquesina que avanza con el nombre de la institución. El edificio resta así prioridad al acceso ya que enfatiza su escala respecto a la avenida sobre la que se sitúa.

(Ver fotos 18, 19, 20. Colegios Alemán y Guadalaviar).

Un aspecto común a los colegios Guadalaviar y Alemán es el de la búsqueda de la continuidad visual a través de recorridos secuenciales sugeridos por la presencia de cuerpos que, en términos miesianos, ceden su planta baja para ser atravesados. Las edificaciones contribuyen a configurar un armonioso paisaje artificial, con ambientes confortables y funcionalmente articulados en planta.

En los colegios Guadalaviar y Alemán los espacios exteriores quedan pautados a partir de la métrica del edificio, entendidos como una sucesión de ámbitos por los que se extiende el proyecto del interior al exterior, incluyendo pasarelas, espacios cubiertos y jardines.

El Guadalaviar plantea dos ámbitos exteriores: El patio de acceso generado por la disposición en $U$ del cuerpo principal en el que los pavimentos de hormigón, bancos y jardineras se 

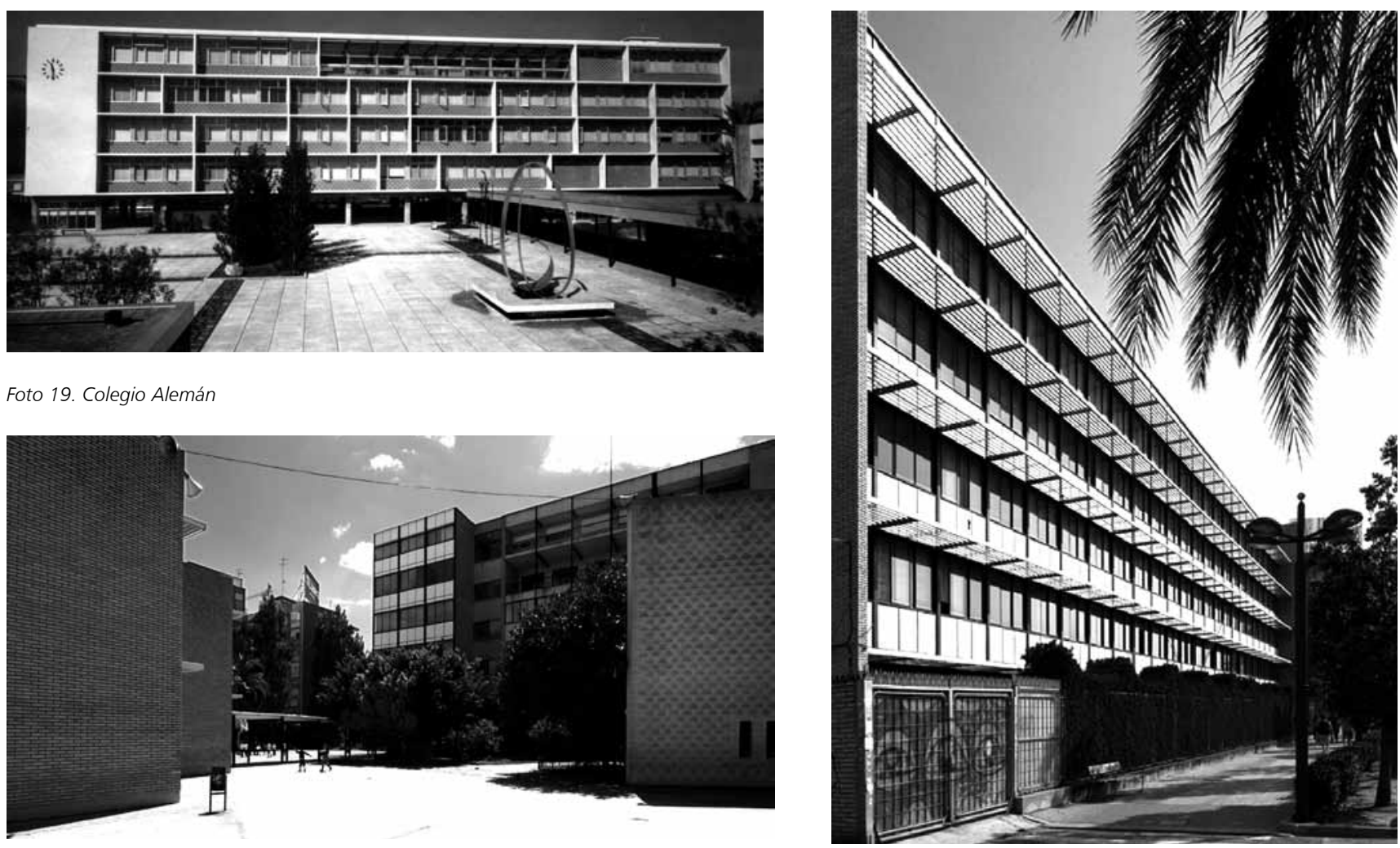

Foto 19. Colegio Alemán

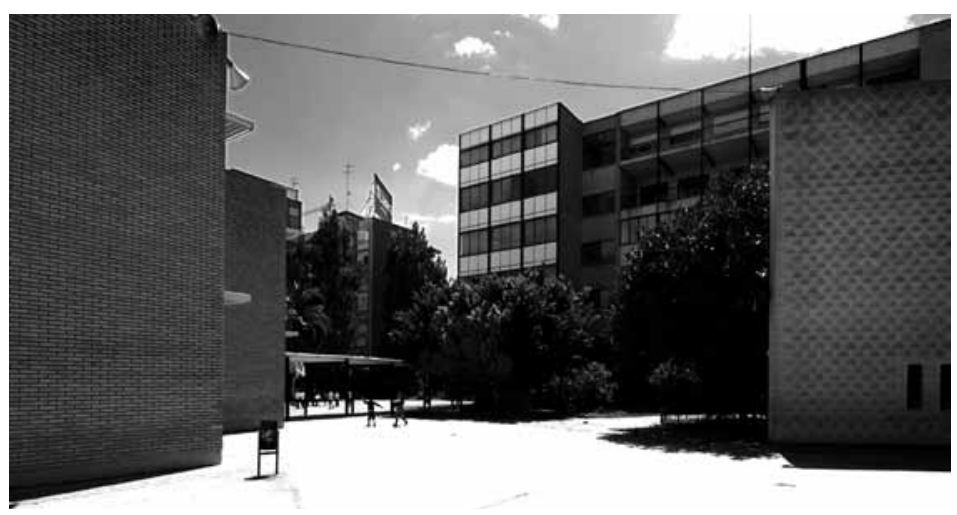

diseñan con submódulos de la pauta estructural. El segundo ámbito se sitúa en la zona posterior sur, más libre y ajardinada y por la que se deslizan los recorridos peatonales hacia las aulas de infantil, a través del estanque.

Especial interés tiene el diseño de los espacios exteriores del Colegio Alemán, llevados a cabo por el arquitecto catalán N. Rubió i Tudurí. ${ }^{6}$ En el jardín de acceso se distribuyen armoniosamente diferentes especies vegetales que dan la bienvenida al edificio. El patio posterior, que adquiere escala de vacío urbano, queda definido como un tapiz en el que se juega compositivamente con la ubicación de la vegetación y los diferentes tipos de pavimentos.

Los espacios exteriores en el colegio Pureza siguen una estrategia diferente, pues recurren a un lenguaje más tradicional en el que las áreas verdes no dependen de la arquitectura ni de sus leyes estructurales, en los términos planteados en los ejemplos anteriores.

\section{CRITERIOS ESTRUCTURALES Y PLANTA TIPO}

A partir de que la reflexión sobre la estructura ha sido un elemento básico del proyecto moderno, la idea estructural ejerce un papel relevante en la concepción de estos edificios. Los sistemas estructurales planteados en cada uno de los proyectos están caracterizados por una complejidad coherente, en su definición espacial, en su formalización y por las relaciones entre transparencia y opacidad. (Ver figura 4, 5, 6) 
El Guadalaviar y Pureza buscan en su estructura un acercamiento al lenguaje particular de las estructuras metálicas miesianas con el desplazamiento de los perfiles metálicos desde el interior del plano de fachada al exterior de la misma.

El Alemán resuelve su estructura en hormigón al aumentar las luces de vano en la planta baja para conseguir una mayor diafanidad y buscar estabilidad estructural con el volumen de la escalera que se proyecta al exterior.

La utilización de estos sistemas permite una mayor libertad compositiva de las fachadas que incorporan criterios de modernidad arquitectónica como una mayor relación interiorexterior mediante la incorporación de grandes aberturas, la repetición de unidades de huecos o la libertad que se consigue en planta baja al independizar cerramientos de estructura y diluir el zócalo del edificio.

La distribución de las plantas queda ligada a las características de los sistemas estructurales y modulaciones elegidos. Coinciden los tres colegios en situar en una primera crujía las aulas, pues buscan la mejor orientación y una proporción adecuada. En una segunda crujía se resuelven los corredores con dimensiones que varían desde los 2,20 a los $2,50 \mathrm{~m}$, ya que destacan en los tres casos la relación directa que se establece con el exterior, y particularmente en el Pureza con las terrazas que vuelcan al jardín posterior.
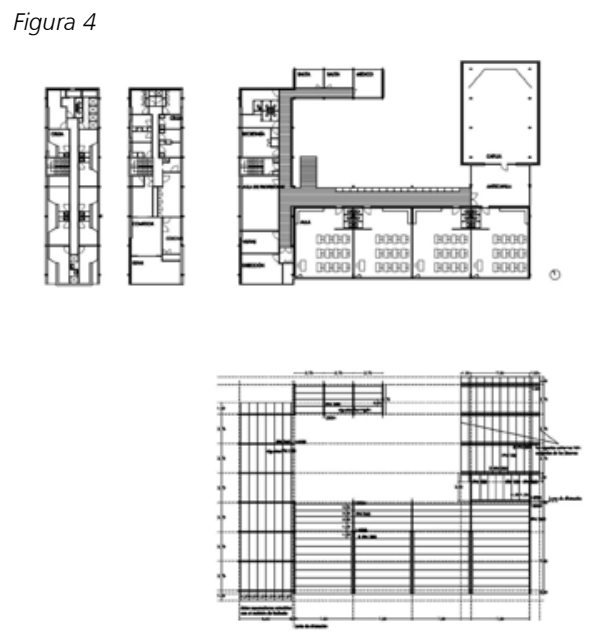

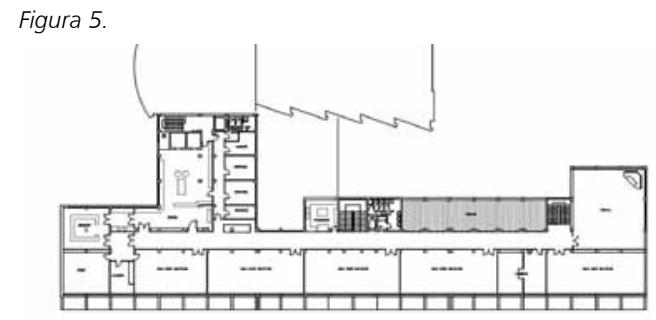

Figura 5.

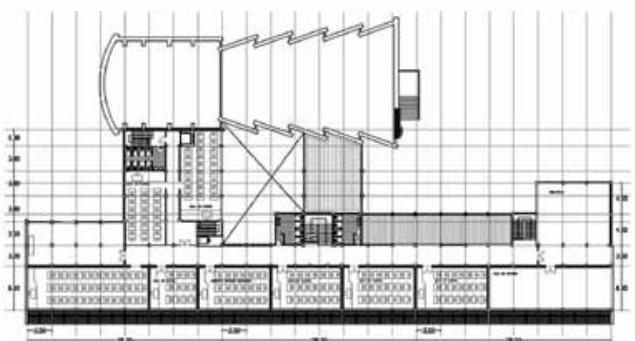

Figura 6.
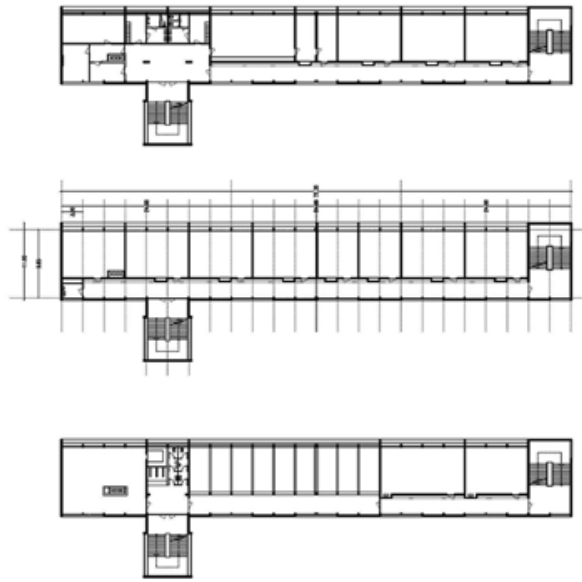
Se evitan aulas con orientaciones diferentes y corredores interiores sin iluminación natural ni relación con el exterior, y se valorizan los espacios comunes. Se busca la ventilación cruzada de las aulas a través de los corredores en el Alemán y Pureza o bien directamente hacia el exterior a través del juego del plano de cubiertas en el Guadalaviar.

La profundidad de las aulas viene generada por la modulación estructural con luces que varían desde los 7,50m en el Guadalaviar y los 6,90 y 6,40m en el Alemán y Pureza. La excesiva profundidad en el primer caso, lleva a buscar soluciones de iluminación natural de norte.

La elección de las dimensiones de vano se resuelven con 3 y 3,5m en el en el Alemán y Pureza lo que permite generar aulas de dimensiones diversas que atienden a las particularidades programáticas de este tipo de edificios sin afectar a la composición de la fachada. La dimensión de 7,5m en el Guadalaviar, resulta excesiva para asumir los cambios dimensionales, como se ha comprobado con posterioridad.

\section{FACHADAS: COMPOSICIÓN, MATERIALIDAD Y RELACIÓN INTERIOR-EXTERIOR}

(Ver Fotos 21, 22, 23, 24, 25 Colegio Alemán y Colegio Pureza)

Foto 21
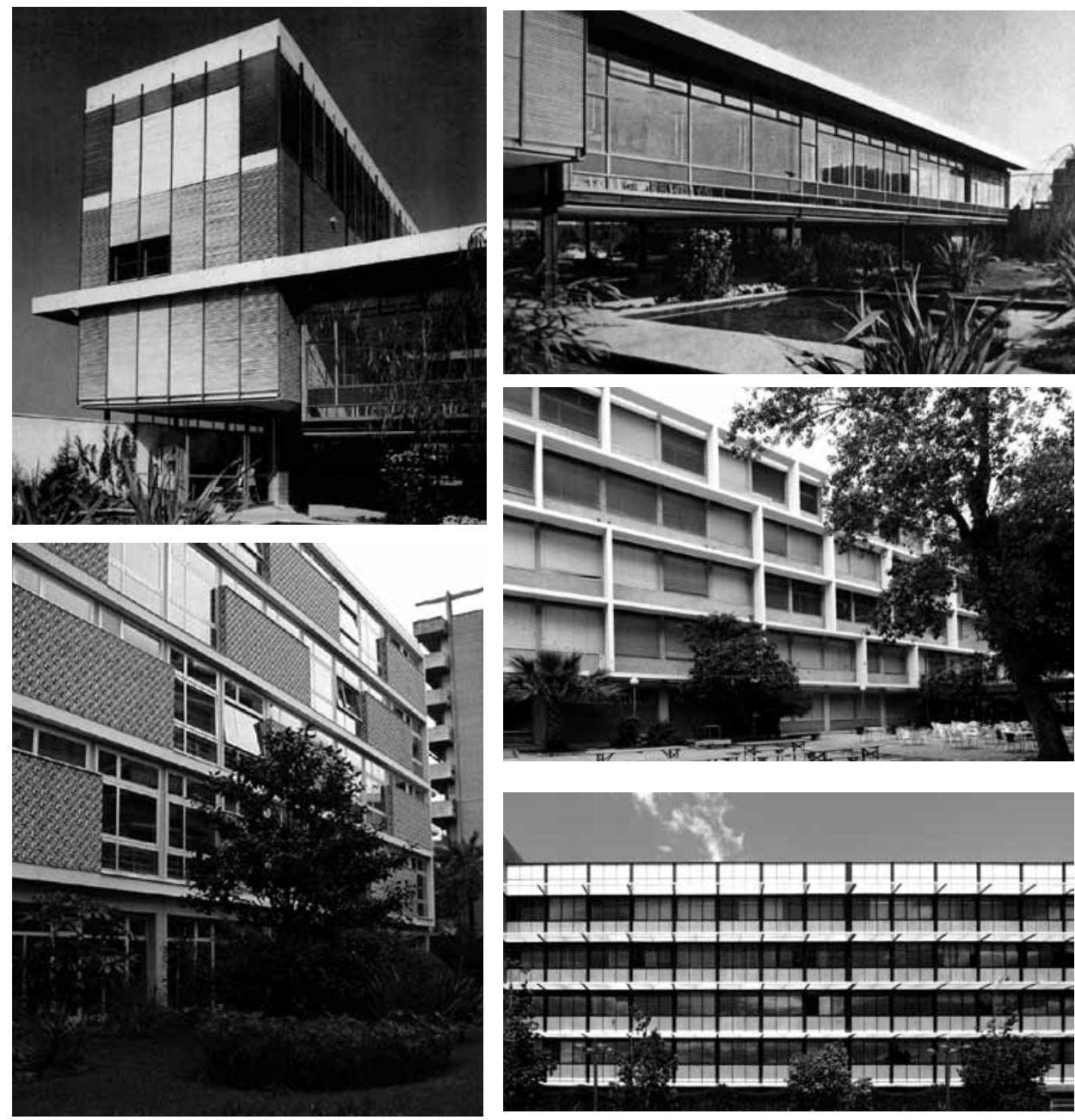
La composición de las fachadas, su materialidad y la relación interior-exterior que se produce a través de ella a partir del estudio de aspectos como la iluminación, la ventilación y los elementos de protección solar, contribuyen de manera decisiva a la definición del lenguaje moderno de cada uno de los edificios.

La composición se realiza a partir del orden estructural que se revela al exterior, pues busca la seriación de elementos y partes y diferencia su tratamiento según las diversas orientaciones y funciones al interior con la contraposición de macizos y huecos.

La fachada del Pureza queda enmarcada entre los dos muros de ladrillo que lo acotan, como un gran telón de fondo, en el que se revela la modulación estructural que imprime un ritmo continuo y pautado.

Las carpinterías colaboran en la definición de la fachada con el despiece entre partes fijas y practicables de líneas neoplásticas en el caso del Guadalaviar y Alemán y tripartita en el Pureza.

materialidad se resuelve desde la racionalidad y la sinceridad constructiva, con referencias a lo local como la utilización de piezas exclusivas de gres cerámico Nolla en los fragmentos murarios de la fachada principal del colegio Alemán o el ladrillo caravista en los otros dos edificios.

un especial interés hacia el detalle y la aplicación de nuevas tecnologías, como sucede en el cuerpo principal del Guadalaviar con la introducción de lamas metálicas orientables o el panel de glasal que define los paramentos opacos blancos en el Pureza.

La relación interior-exterior es particularmente interesante a través de los elementos de protección solar planteados, como sistemas que dotan de significado a la arquitectura, ya que más allá de la función de soleamiento, proporcionan una imagen de modernidad y abstracción.

El volumen de aulas del Guadalaviar se protege por una marquesina que recorre todo el conjunto y cuyo vuelo fue calculado para evitar que el sol en su máxima altura penetrase más allá de un metro en la planta del aula.

La fachada Este del colegio Alemán imprime un nuevo ritmo a la modulación estructural con la incorporación de unos significativos parasoles de hormigón definidos mediante rectángulos de diferentes longitudes.

La fachada principal del colegio Pureza de 85m de largo y orientación Este queda enfatizada por el contraste entre luz y sombra que le imprimen las marquesinas metálicas dispuestas en perpendicular a la fachada. 


\section{LOS PABELLONES DE INFANTIL}

(Ver Foto 26 y 27 y Figuras 7, 8, 9)

Merece un tema de análisis independiente el estudio de los pabellones donde se ubican las aulas de parvulario, ya que en los tres conjuntos escolares, éstos aparecen como volúmenes independientes, ligados por la lógica de la orientación y la necesidad de buscar espacios abiertos que favorezcan el contacto de los niños con la vida al aire libre.

La vinculación con los edificios mayores se establece mediante pasarelas cubiertas dispuestas en perpendicular al cuerpo alto, en los pabellones del Alemán y Pureza y mediante caminos a modo de sutiles líneas de enlace en el caso del Guadalaviar, así adquiere el aspecto de arquitectura diseminada entre jardines.

Si bien la estrategia seguida en cada caso en diferente, cada edificio busca conseguir la mayor relación con el exterior a través de la apertura de la esquina de orientación sureste.

Para ello, el Guadalaviar dispone cada "unidad pedagógica" de forma escalonada, pues propone un espacio de extensión de cada aula hacia el exterior.

Los otros dos edificios plantean pequeñas construcciones autónomas que mediante la disposición en peine en el caso del Alemán y la disposición dentada en el del Pureza se resuelve un sistema de aulas vinculado a un recorrido de circulación interior y usos anexos.

En este último caso, cada aula no disfruta de un espacio exterior vinculado, pero sí de un exterior que lo envuelve y protege con vegetación, con un porche común que recompone el volumen en la parte posterior.

Las condiciones climáticas particulares de la ciudad de Valencia, hacen relevante, el papel que juegan los sistemas de protección solar y de ventilación. En los tres edificios se resuelve con la prolongación del alero o la incorporación de marquesinas metálicas. El recurso utilizado para permitir circulaciones cruzadas de aire es similar en todas ellas, practican
Foto 25 .

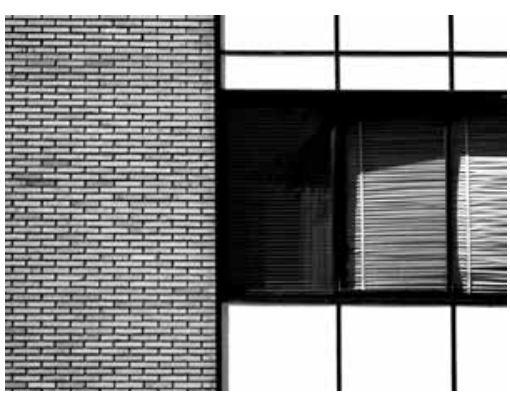

Figura 7.
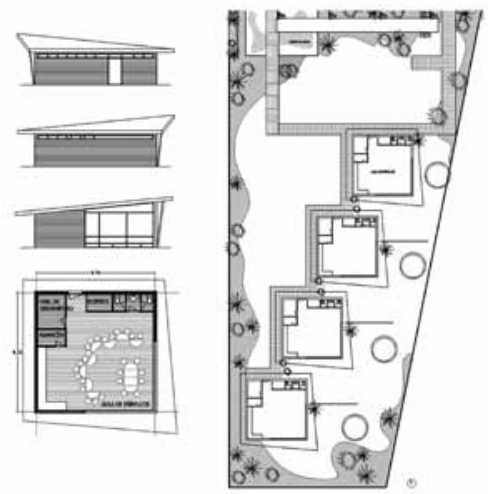

Foto 26.

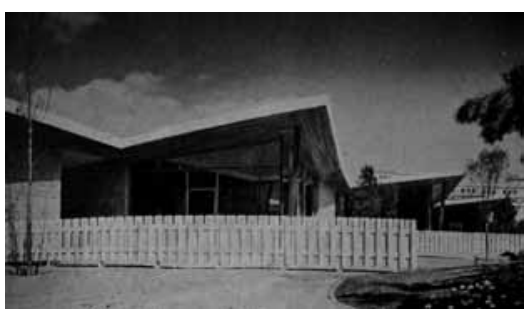

Figura 8.
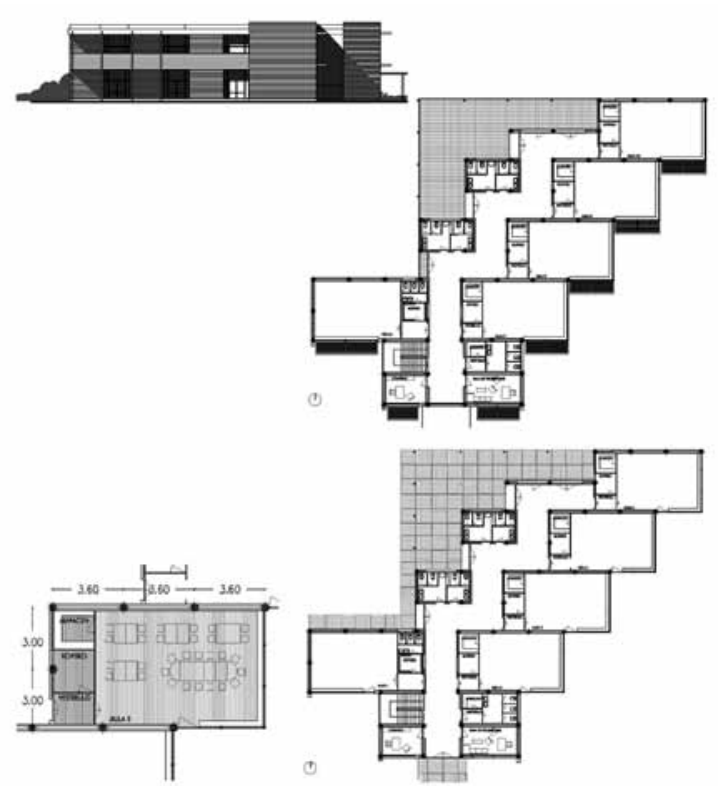

Figura 9.
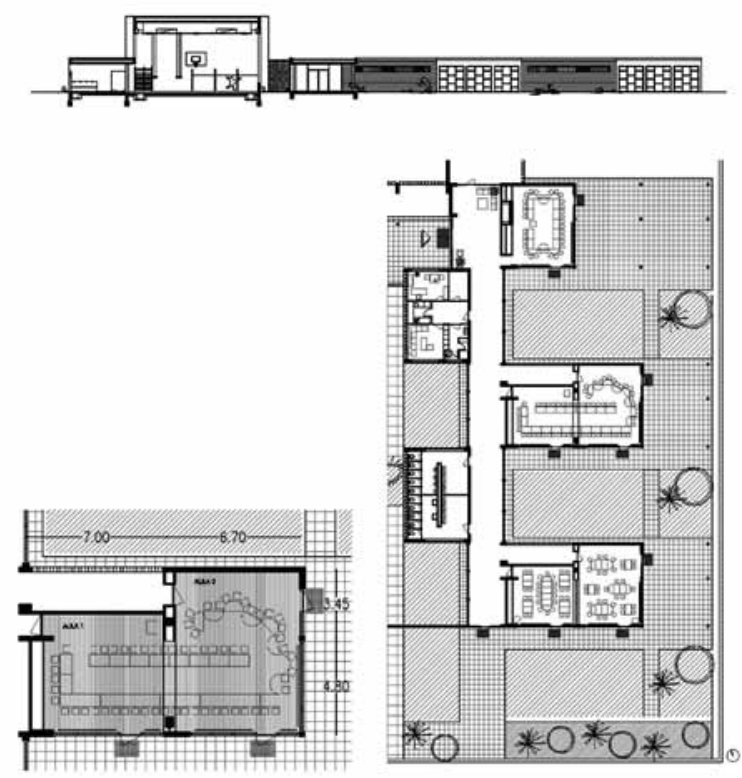
aberturas superiores en los cerramientos opuestos a los acristalados, pues psobilita que el aire caliente generado en el interior escape por debajo de la cubierta.

El Guadalaviar propone unidades individuales de aulas que mediante la agrupación de los espacios de servicio en forma de $L$ organiza el espacio exterior.

En el caso del Alemán las unidades son ampliables hacia un porche exterior y hacia el jardín a sur como extensión lógica del aula. El sistema conseguido permite disfrutar de espacios flexibles e intermedios ricos en matices.

\section{CONCLUSIONES}

El análisis de las estrategias utilizadas en cada proyecto, la aplicación de los parámetros de repetición, economía e higiene y las condiciones particulares de los programas docentes que permiten la construcción a partir de sistemas, nos lleva a observar analogías importantes en el planteamiento arquitectónico de cada uno de los edificios:

\section{Implantación en el solar. Organización de los volúmenes}

Organización de cada proyecto como una unidad construida a partir de la articulación de distintos fragmentos funcionales: aulas y administración, capilla o gimnasio-salón de actos y pabellones de infantil.

Disposición volumétrica con gran influencia de la orientación, que evita las pérdidas de iluminación por la proyección de sombras.

Volúmenes cuidadosamente dispuestos en función de la visualización del conjunto y de su adecuada proporción, con giros ortogonales y desplazamientos entre las partes, pues genera espacios exteriores.

Relectura en clave moderna del patio tradicional: patios con límites no absolutos, permeables pero no precisos, donde se elimina uno de los frentes construidos (idea de "patio descentralizado").

\section{Configuración del acceso. Diseño de los espacios exteriores}

Ausencia de monumentalidad en el punto de acceso, pues prima la importancia concedida al lugar y a la definición de los espacios exteriores.

Continuidad visual y recorridos secuenciales sugeridos por la presencia ocasional de cuerpos que ceden su planta baja para ser atravesados.

Espacios exteriores organizados a partir de la métrica del edificio, entendidos como una sucesión de ámbitos por los que se extiende el proyecto del interior al exterior, que incluye pasarelas, espacios cubiertos y jardines.

La vegetación y el agua como elementos naturales capaces de construir espacios. 


\section{Criterios estructurales y planta tipo}

Reflexión sobre la estructura como elemento básico del proyecto moderno.

Sistemas estructurales caracterizados por una complejidad coherente con las concepciones de cada edificio: definición espacial, formalización y relación entre transparencia y opacidad.

Distribución de las plantas ligadas a las características de los sistemas estructurales elegidos.

Búsqueda de luz natural y de una proporción adecuada de las aulas, que da valor a los espacios comunes.

\section{Fachadas: composición, materialidad y relación interior-exterior}

Racionalidad y sinceridad constructiva, con referencias a lo local y con especial interés hacia el detalle y la aplicación de nuevas tecnologías.

Relación interior-exterior a partir del estudio de la iluminación, la ventilación y los elementos de protección solar, como sistemas que dotan de significado a la arquitectura.

Composición de las fachadas a partir del orden estructural que se revela al exterior, pues busca la seriación de elementos y partes y diferencia su tratamiento según las diversas orientaciones $y$ funciones al interior.

Por último, cabría destacar que la durabilidad de las construcciones es mucho mayor que la de los factores pedagógicos, por lo que la arquitectura escolar debe responder a una gran simplicidad con el fin de permitir un mayor grado de libertad en su utilización. Aspecto que ya tuvo en cuenta el arquitecto suizo Alfred Roth, especialista en construcciones escolares y que en su libro "La nouvelle Ecole" de 1957 defendía que el niño es el sujeto y no el objeto de la educación y que por lo tanto la arquitectura debe situarse a su escala y evitar los edificios monumentales.

\section{BIBLIOGRAFÍA}

ARQUITECTURA DEL MOVIMIENTO MODERNO. REGISTRO DOCOMOMO IBÉRICO. 1925-1965. Dirección: Xavier Costa y Susana Landrove. 1996. Barcelona. Ed. Fundación Mies van der Rohe.

20X20. SIGLO XX. VEINTE OBRAS DE ARQUITECTURA MODERNA. Catálogo de la exposición. Dirección: Carmen Jordá Such. 1997. Valencia. Ed. Generalitat Valenciana, COPUT Y COACV.

REGISTRO DE ARQUITECTURA DEL SIGLO XX. COMUNIDAD VALENCIANA. 2 vols. Dirección: Vicente Colomer Sendra. 2002. Valencia. Ed. COACV, COPUT de la Generalitat Valenciana e IVE con la colaboración de la UPV.

ALFRED ROTH. La Nouvelle Ecole. Ed. Girsberger. I ${ }^{a}$ edición. Zurich. 1957. 
GIMÉNEZ JULIÁN Emilio y LLORENS SERRA Tomás. "La imagen de la ciudad de Valencia” En: Rev.: HOGAR Y ARQUITECTURA Enero/febrero. n 86. (Pág. I 3- | 44). 1970.

JORDÁ SUCH, Carmen. "Valencia: Territorio y arquitectura. Una lectura particular. En: "Rev.: GEOMETRÍA n 13: "Arquitectura valenciana: itinerarios de la historia reciente" (Pág. 38-7I) 1992. Málaga.

1997. Valencia.

. "Referencias de la modernidad en la Comunidad Valenciana”. En: Rev.: V-iA

TORRES CUECO, Jorge. "Luz de levante. Castellón, Valencia y Alicante. Fervor mediterráneo." "Valencia moderna. Del eclecticismo a la tendenza" En: Rev.: ARQUITECTURA VIVA No 6I. (Pág. 17-23.) 1998. Madrid.

AMANDO LLOPIS Alonso y DAUKSIS Sonia. Arquitectura del siglo $\mathbf{X X}$ en Valencia. “1940-1959. Arquitectura Moderna en Valencia." Colección Formas Plásticas n 9. Eds. Institució Alfons el Magnànim-Diputació de València. 200I. Valencia.

Arquitectura y transformación urbana de la ciudad de valencia. "Valencia en los años finales de la década de 1950. Ejemplos de modernidad en la arquitectura pública." Vol. 3. Historia de la ciudad. COACV, Ayuntamiento de Valencia y la Universitat de Valencia. 2004. Valencia.

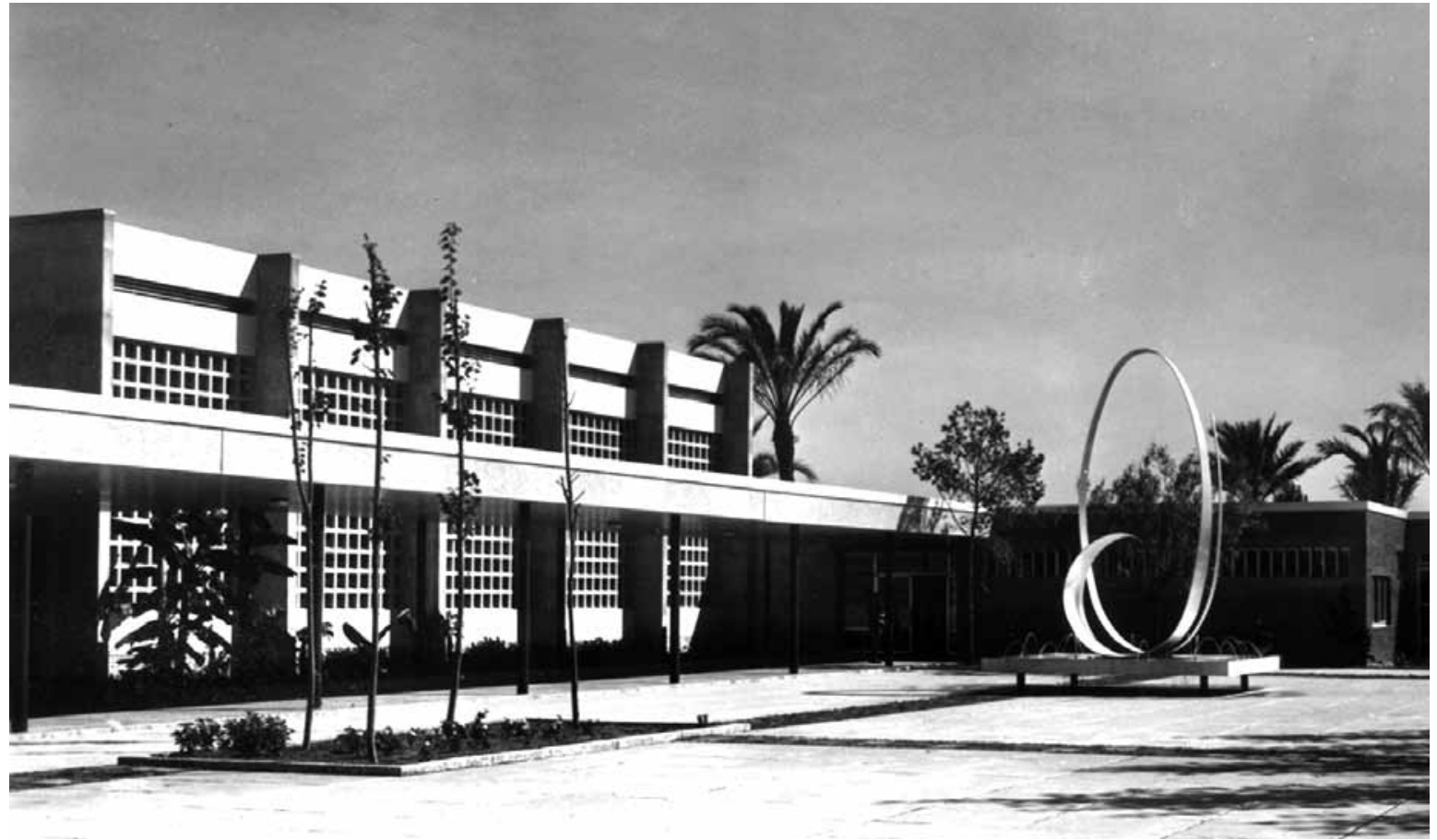


NAVARRO ALVARGONZÁLEZ, Pablo. "Proyecto para el Colegio Alemán de Valencia." En: Rev.: ARTE VIVO n². 1959. Valencia. Ed. Grupo Parpalló.

GARCÍA-ORDOÑEZ, Fernando M. "Escuela-jardín en Valencia." En: Rev.: Informes de la Construcción nI25. (Pág. I4I-160). 1960. Noviembre. Madrid. Ed. Instituto Eduardo Torroja.

. “École -Jardin, Valence, Espagne." En: Rev: L'Architecture d'Aujourd'hui. No 94. Enseignement. (Pág. 26-29) 196I. Fevrier-Mars. Paris.

. "Escuela jardín de infancia en Valencia". En: Rev.: Cuadernos de arquitectura y urbanismo nº 5I. (Pág. 6-II). 1963. ler. Trimestre.

. "School at Valencia." En: Rev.: The Architect \& Building News. V 244/4 Is weekly. (Pág. I4I-I43) I963 24 July. Londres. Ed. Building and Contract Journals.

"Colegio Guadalaviar" En: Rev.: Temas de arquitectura n 147. (Pág. 6I-67). GO-DB Arquitectos. 197I. Septiembre.

MARTÍNEZ BALLESTER, Enrique. Rev.: Arquitectura n 184. "GO-DB, arquitectos asociados" Entrevista. (Pág. 2-10) 1974. Abril.

Foto 28. Colegio Cuadalaviar.

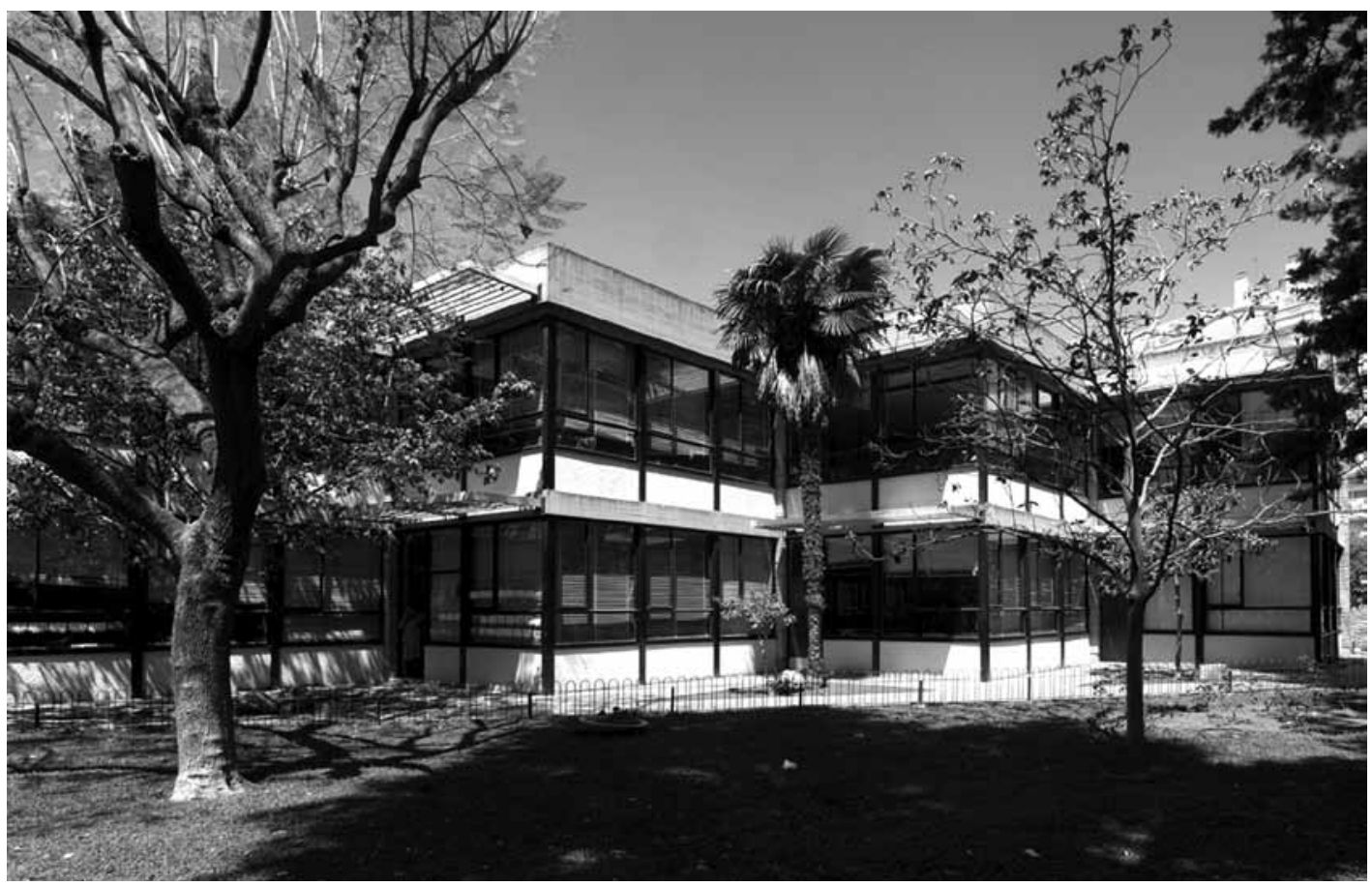

